\section{Pacific Northwest}

\section{National Laboratory}

Operated by Battelle for the

U.S. Department of Energy

\section{Investigation of Isotopic Signatures for Sources of Groundwater Contamination at the Hanford Site}

\author{
P. E. Dresel \\ J. C. Evans \\ O. T. Farmer III
}

January 2002

Prepared for the U.S. Department of Energy under Contract DE-AC06-76RL01830 


\section{DISCLAIMER}

This report was prepared as an account of work sponsored by an agency of the United States Government. Reference herein to any specific commercial product, process, or service by trade name, trademark, manufacturer, or otherwise does not necessarily constitute or imply its endorsement, recommendation, or favoring by the United States Government or any agency thereof, or Battelle Memorial Institute.

\section{PACIFIC NORTHWEST NATIONAL LABORATORY \\ operated by \\ BATTELLE \\ for the \\ UNITED STATES DEPARTMENT OF ENERGY \\ under Contract DE-AC06-76RL01830}

Printed in the United States of America

Available to DOE and DOE contractors from the

Office of Scientific and Technical Information, P.O. Box 62, Oak Ridge, TN 37831;

prices available from (615) 576-8401.

Available to the public from the National Technical Information Service, U.S. Department of Commerce, 5285 Port Royal Rd., Springfield, VA 22161

This document was printed on recycled paper. 


\title{
Investigation of Isotopic Signatures for Sources of Groundwater Contamination at the Hanford Site
}

\author{
P. E. Dresel \\ J. C. Evans \\ O. T. Farmer III
}

January 2002

Prepared for

the U.S. Department of Energy

under Contract DE-AC06-76RL01830

Pacific Northwest National Laboratory

Richland, Washington 99352 


\section{Summary}

Isotopes of several elements were measured in groundwater to provide a more complete characterization of contaminants. The additional species are expected to help identify contaminant sources and to aid interpretation of contaminant transport mechanisms by providing "signatures" of particular sources and plumes. Most of the work reported here involved development of techniques for analysis by inductively coupled plasma-mass spectrometry. These include the analysis of uranium, plutonium, ruthenium, and molybdenum isotopes. In addition to these, a survey of analyses by accelerator mass spectrometry for chlorine-36 in groundwater is reported.

Uranium isotopic composition of the groundwater samples is affected by natural variations due to alpha-recoil effect as well as the composition of contamination. Uranium isotopes from irradiated Hanford fuel depend on the fuel enrichment as well as reactor conditions and irradiation time. A nuclear model of Hanford reactors provides calculated uranium isotopic composition for each fuel load processed at Hanford. The groundwater data can be matched to the model results. Many of the 200 East Area samples are consistent with a source from early Hanford production. Other Site samples are consistent with sources of depleted uranium and commercial, enriched reactor fuel.

Plutonium isotopic compositions of samples collected near the 216-B-5 injection well are easily distinguishable from fall out and match the nuclear model calculation of the product from the period when the facility was used.

Ruthenium found in groundwater in the 200 East Area clearly has a fission source. The technetium99:ruthenium-101 ratio is higher than expected from the fission yield - i.e., ruthenium is depleted with respect to fission. Several samples in the southeast part of the plume near the B tank farm, have very high technetium-99:ruthenium-101 ratios, while samples from further northwest have lower ratios. This suggests there may be separate technetium-99 sources in the area. One sample from the 200 West Area showed detectable ruthenium with natural isotopic abundances.

Molybdenum in groundwater samples did not show fission isotopic abundances and appears to be a natural trace constituent in groundwater. In contrast, vadose zone samples from the tank leak at tank SX-108 in the 200 West Area clearly show the presence of fission molybdenum.

Abundant chlorine-36 was detected in Hanford groundwater in areas impacted by site contamination. The highest concentration was from the $100 \mathrm{~F}$ Area. The chlorine- 36 is an activation product that is highly mobile in the subsurface and thus may be useful in source attribution. 


\section{Contents}

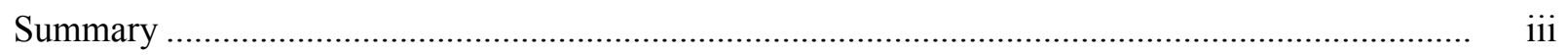

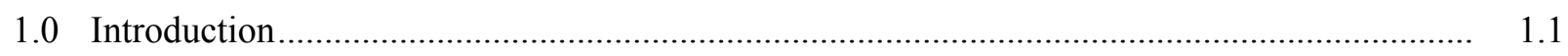

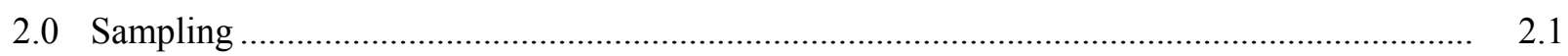

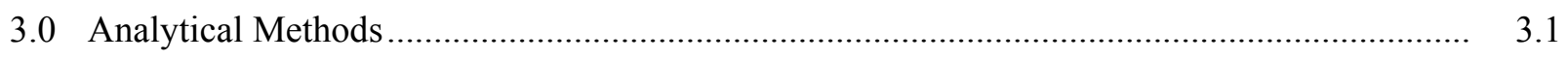

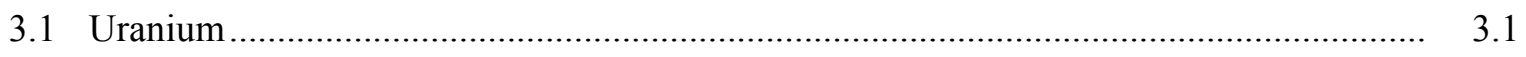

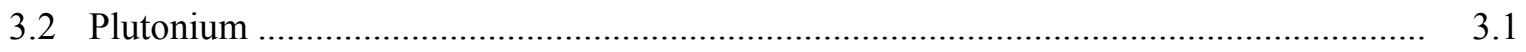

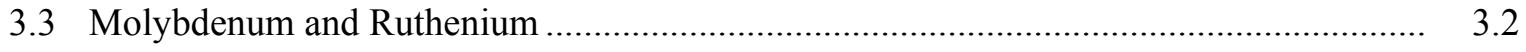

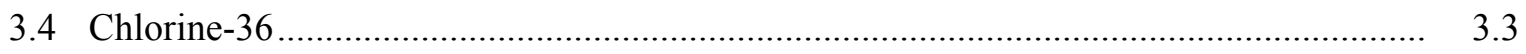

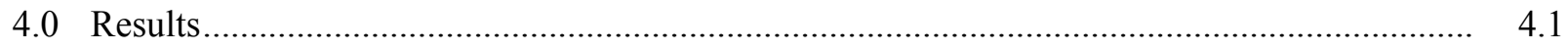

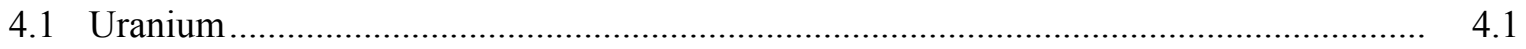

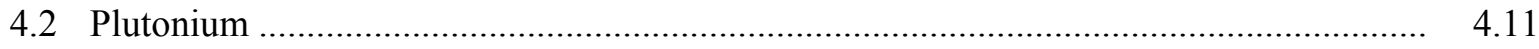

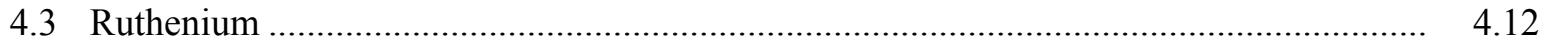

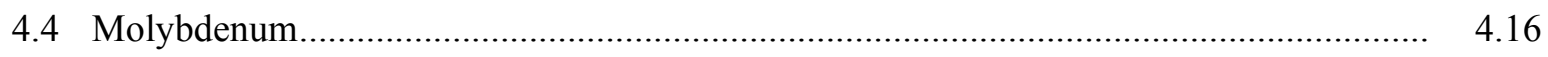

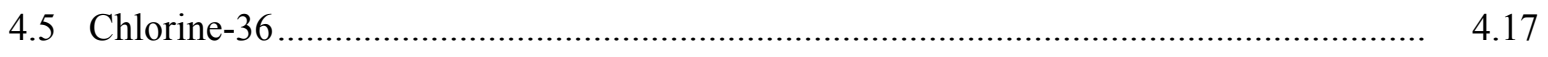

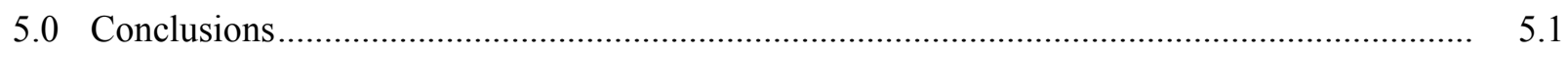

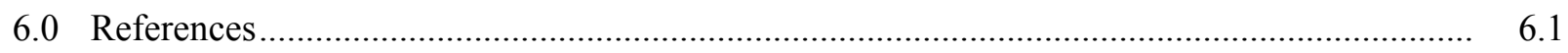




\section{Figures}

1.1 Uranium-234 Abundance for Hanford Reactor Fuel ...................................................... 1.3

1.2 Uranium-235 Abundance for Hanford Reactor Fuel ........................................................

1.3 Uranium-236 Abundance for Hanford Reactor Fuel ........................................................

1.4 Uranium-236 versus Uranium-235 Abundance for Hanford Reactor Fuel ............................ 1.6

1.5 Fission Yield Curves for Uranium-235 and Plutonium-239....................................... 1.7

4.1 Uranium-234 and Uranium-235 Abundance in Groundwater Samples, Normalized to

Natural Isotopic Abundance

4.2 Uranium-236 versus Uranium-235 Abundance for Hanford Groundwater Samples, Compared to Hanford Reactor Fuel.

4.3 Uranium Concentration and Uranium-236 Abundance for Samples from the Vicinity of the BY Cribs and B-BX-BY Tank Farms in the 200 East Area....

4.4 Detail of Uranium-236 Abundance for Hanford Reactor Fuel from the Early Production

4.5 Uranium-236 Abundance for Groundwater Samples from Richland North.

4.6 Relative Abundance of Ruthenium-101 to the Sum of Ruthenium-101, -102, -104 in Hanford Groundwater Samples Compared to Natural and Fission Ratios

4.7 Relative Abundance of Ruthenium-102 to the Sum of Ruthenium-101, -102, -104 in Hanford Groundwater Samples Compared to Natural and Fission Ratios

4.8 Relative Abundance of Ruthenium-104 to the Sum ofRuthenium-101, -102, -104 in Hanford Groundwater Samples Compared to Natural and Fission Ratios

4.9 Ruthenium-101:Ruthenium-104 Ratio versus Ruthenium-102:Ruthenium-104 Ratio for Hanford Groundwater Samples Compared to Natural and Fission Ratios

4.10 Technetium-99:Ruthenium-101 Ratios in the Vicinity of the BY Cribs and B-BX-BY Tank Farms.

4.11 Abundance Ratio of Molybdenum-98 to Total Molybdenum-95, -97, -98, and -100 for Hanford Groundwater Samples

4.12 Comparison of Total Molybdenum in Water Extracts from SX-108 Slant Borehole with Fission Derived ${ }^{100} \mathrm{Mo}$

4.13 Chlorine-36 Concentration Compared to Tritium for Hanford Groundwater Samples 


\section{Tables}

1.1 Date Ranges for Uranium Fuel Types Processed by Hanford Plants ................................. 1.2

4.1 Uranium Isotopic Concentrations in Samples from the Hanford Site ................................. 4.2

4.2 Uranium Isotopic Abundance in Samples from the Hanford Site .....................................

4.3 Locations of Low Abundance Uranium-236 Samples in the 200 East Area ......................... 4.7

4.4 Uranium Isotopic Estimates for Tank Leaks in the B-BX-BY Tank Farms........................ 4.8

4.5 Uranium Isotopic Composition in Samples South of the 300 Area.................................... 4.9

4.6 Results of Plutonium Analysis by ICP-MS with Preconcentration/Separation ..................... 4.11

4.7 Isotopic Ratios of Ruthenium from Natural and Fission Abundance .................................. 4.12

4.8 Isotopic Ratios of Ruthenium in Hanford Groundwater Samples ....................................... 4.13

4.9 Concentrations of Ruthenium Isotopes and Total for the Three Quantified Isotopes in

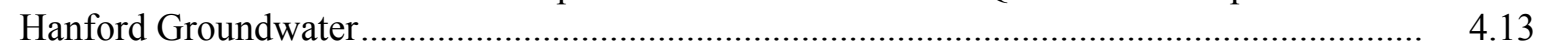

4.10 Technetium-99, Rhodium-103, and Palladium-105 Ratios to Ruthenium-101 in Groundwater Samples from the 200 East Area, near the BY Crib and the B-BX-BY Tank Farms .....

4.11 Molybdenum Isotopic Abundance in Hanford Groundwater Samples................................ 4.19

4.12 Relative Isotopic Ratio of Molybdenum-95, -97, -98, and -100 in Hanford Groundwater

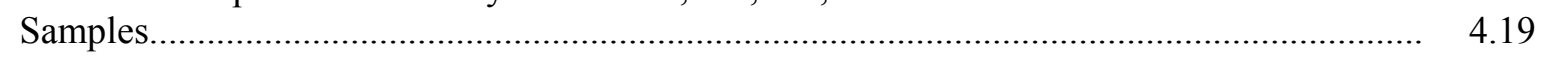

4.13 Chlorine-36 Measurements of Hanford Groundwater ................................................ 


\subsection{Introduction}

The Hanford Site Groundwater Monitoring Project at Pacific Northwest National Laboratory (PNNL) investigated selected isotopic signature techniques to aid interpretation of contaminant plumes in Hanford Site groundwater. The main approach was to select groundwater samples expected to exhibit a variety of contaminant characteristics and then develop inductively coupled plasma mass spectrometry (ICP-MS) analytical methods for the groundwater matrix. Initial broad scans were used to identify interferences and to focus the method development on isotopes showing the greatest promise of practical application. In addition, earlier work characterizing chlorine-36 in Hanford Site groundwater by accelerator mass spectrometry (AMS) will be discussed.

The ICP-MS methods initially focused on plutonium isotopes and uranium isotopes. Preliminary work has been performed on ruthenium and molybdenum isotopes. Further work on vadose zone samples has substantially improved the methods for cesium, iodine, selenium, and other constituents but the methods not been applied to groundwater samples.

The work discussed here links closely with several other projects and activities. Initial method development for some of the isotopes of interest was performed under a PNNL Laboratory Directed Research and Development project. Isotopic signature work also has been carried out on water and acid leaches of vadose zone samples. Those samples were collected from the SX tank farm in the $200 \mathrm{West}$ Area. The plutonium isotopic samples were collected as part of a colloidal transport study and the ICP-MS results were critical to that investigation. An issue regarding the presence of low levels of tritium contamination in the Richland North Area arose while the isotopic signature investigation was taking place. The ICP-MS method developed in this study was used to characterize low levels of uranium in the Richland North Area groundwater in conjunction with that investigation.

Cleanup of contamination at the Hanford Site is complicated by the presence of multiple sources in close proximity. In many cases, it is difficult to associate groundwater effects with specific sources. The resulting uncertainty in assessment of contaminant fate and transport leads to a corresponding difficulty in determining appropriate groundwater and source remediation measures needed to protect human health and the environment.

Groundwater contamination at the Hanford Site is the result of decades of nuclear production and processing. The different waste streams from the processes have varying levels of contaminants. However, many of the contaminants are found in multiple waste streams and were discharged or leaked from multiple facilities. Waste compositions changed through the production history because of improvements in reactor operations and in separation processes. Knowledge of these changes provides a theoretical basis for the belief that more detailed investigation of groundwater geochemistry can help unravel the contaminant sources. In particular, this report considers the application of improved analysis of chemical isotopes to evaluate the sources of groundwater contaminant.

Nuclear reactors produce a multitude of new isotopes as fission products and activation products. The primary goal of Hanford Site operations was to produce plutonium-239 through neutron capture on 
uranium-238. The uranium-239 produced by the neutron capture subsequently beta decayed to neptunium-239, then to plutonium-239. As the fuel continued to be irradiated in the reactor, subsequent neutron capture produced plutonium-240 and lesser amounts of plutonium-241 and plutonium-242. In addition, as plutonium-239 built up in the fuel it contributed to the fission to an increasing degree. Thus, the ratio of the plutonium isotopes in the fuel product was a complicated function of fuel composition, reactor conditions, and residence time in the reactors. The isotopic ratios were subsequently modified by radioactive decay. Decay mainly affects the proportion of plutonium-241 due to its relatively short 14.4 year half-life.

For plutonium production, the reactors were generally operated to produce weapons grade plutonium, which is defined as containing less than 7\% plutonium-240 by weight (DOE 1996). Unless stated otherwise, in this document, isotopic percentages refer to weight percent and isotopic abundances are atomic abundances. Fuel grade plutonium contains $7-19 \%$ plutonium-240 and power reactor grade contains greater than 19\% plutonium-240. Hanford produced fuel grade plutonium in 1964 through 1982. Only fuel grade plutonium was produced in 1972 through 1982, which coincides generally with the time period that the processing plants were shut down.

The uranium isotopic composition of the irradiated fuel depended on the isotopic enrichment of uranium-235 (and uranium-234) in the fuel load, the irradiation time, and reactor conditions. The earliest fuel loads at the Hanford Site used unenriched uranium, containing 0.71\% uranium-235, but some later loads were enriched in uranium-235. Beginning in 1958, enriched fuel was used. Unenriched, $0.71 \%$ uranium was processed in all four plants and was the only fuel processed in T Plant and B Plant. Irradiated uranium enriched to $0.94 \%$ and $1.1 \%$ uranium- 235 was processed in the Reduction-Oxidation (REDOX) Plant and the Plutonium-Uranium Extraction (PUREX) Plant. Higher enrichments were only processed in the PUREX Plant. Table 1.1 summarizes the dates and fuel type for the different processing plants.

The uranium isotopic composition altered during the reactor cycle. Uranium-235 burned up through fission and some neutron capture. Uranium-234 also tended to decline due to neutron capture. Although neutron capture on uranium-238 was the direct source of the plutonium-239, overall the percentage of uranium-238 increased with increasing irradiation. Of particular interest is the formation of uranium-236

Table 1.1. Date Ranges for Uranium Fuel Types Processed by Hanford Plants

\begin{tabular}{|c|c|c|c|c|c|}
\hline Facility & $\begin{array}{c}\text { Al-Clad } \\
0.71 \% \text { U-235 } \\
\text { (AL-0.71U) }\end{array}$ & $\begin{array}{c}\text { Al-Clad } \\
0.94 \% \text { U-235 } \\
\text { (AL-0.94U) }\end{array}$ & $\begin{array}{c}\text { Zr-Clad } \\
0.94 \% \text { U-235 } \\
\text { (ZR-0.94U) }\end{array}$ & $\begin{array}{c}\text { Zr-Clad } \\
1.1 \% \text { U-235 } \\
(\mathrm{ZR}-1.1 \mathrm{U})\end{array}$ & $\begin{array}{c}\text { Zr-Clad } \\
2.1 \% \text { U-235 } \\
(\mathrm{ZR}-2.1 \mathrm{U})\end{array}$ \\
\hline T Plant & 1944-1956 & -- & -- & -- & -- \\
\hline B Plant & $1945-1952$ & -- & -- & -- & -- \\
\hline REDOX Plant & $1952-1966$ & 1958-1966 & $1963-1966$ & 1966 & -- \\
\hline PUREX Plant & $1956-1972$ & 1966-1971 & $\begin{array}{c}1967-1972 \\
1983-1988\end{array}$ & $\begin{array}{c}1967-1972, \\
1985-1988\end{array}$ & $1968-1969$ \\
\hline
\end{tabular}


by neutron capture on uranium-235. Uranium-236 has a relatively short half-life and is not present in natural uranium. The presence of uranium-236, thus, is diagnostic of uranium that has been subject to nuclear fission.

The ORIGEN2 computer code has been used to model the isotopic composition of the Hanford production (Watrous and Wootan 1997). ORIGEN2 runs calculated the radionuclide inventory for each fuel type over the range of fuel exposure. A companion code, DKPRO, used the results to calculate the isotopic inventory for each fuel batch processed at Hanford and decay-corrected the radionuclides to 1994. DKPRO interpolates the results with respect to burnup for values that do not match the specific OREGEN2 simulations.

The isotopic abundance of uranium-234 calculated by OREGEN2/DKPRO for each fuel load is shown in Figure 1.1. The uranium-234 abundance varies little for each fuel type. According to the model, the aluminum-clad natural abundance uranium (AL-0.71U) has a distinct uranium-234 abundance, but the other fuel types are very similar.

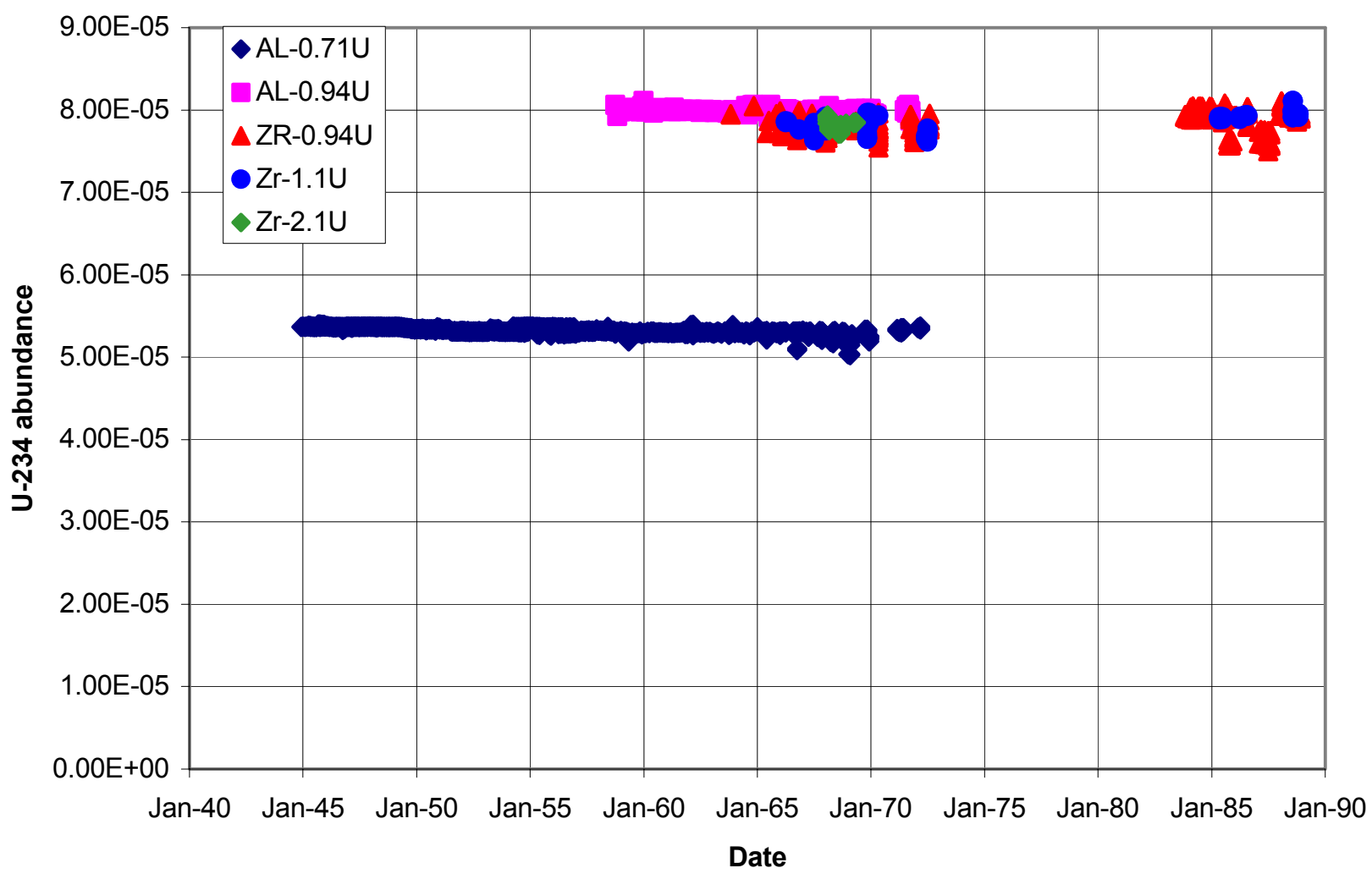

Figure 1.1. Uranium-234 Abundance for Hanford Reactor Fuel. See Table 1.1 for description of fuel types. 
The isotopic abundance of uranium-235 calculated by OREGEN2/DKPRO for each fuel load is shown in Figure 1.2. The post-irradiation uranium-235 abundance for the AL-0.71U is generally distinct from the other fuel types. The aluminum-clad, enriched single-pass reactor fuel (AL-0.94U) maintains a large degree of enrichment after burnup in the reactor. The Zircaloy-clad 0.94\% uranium-235 fuel was the main fuel used at N Reactor and was subject to widely varying burnup. Some of the fuel loads approach natural abundance in uranium-235. The uranium-235 scatter in the other specialty Zircaloy fuels shows they also underwent variable exposure in the reactor.

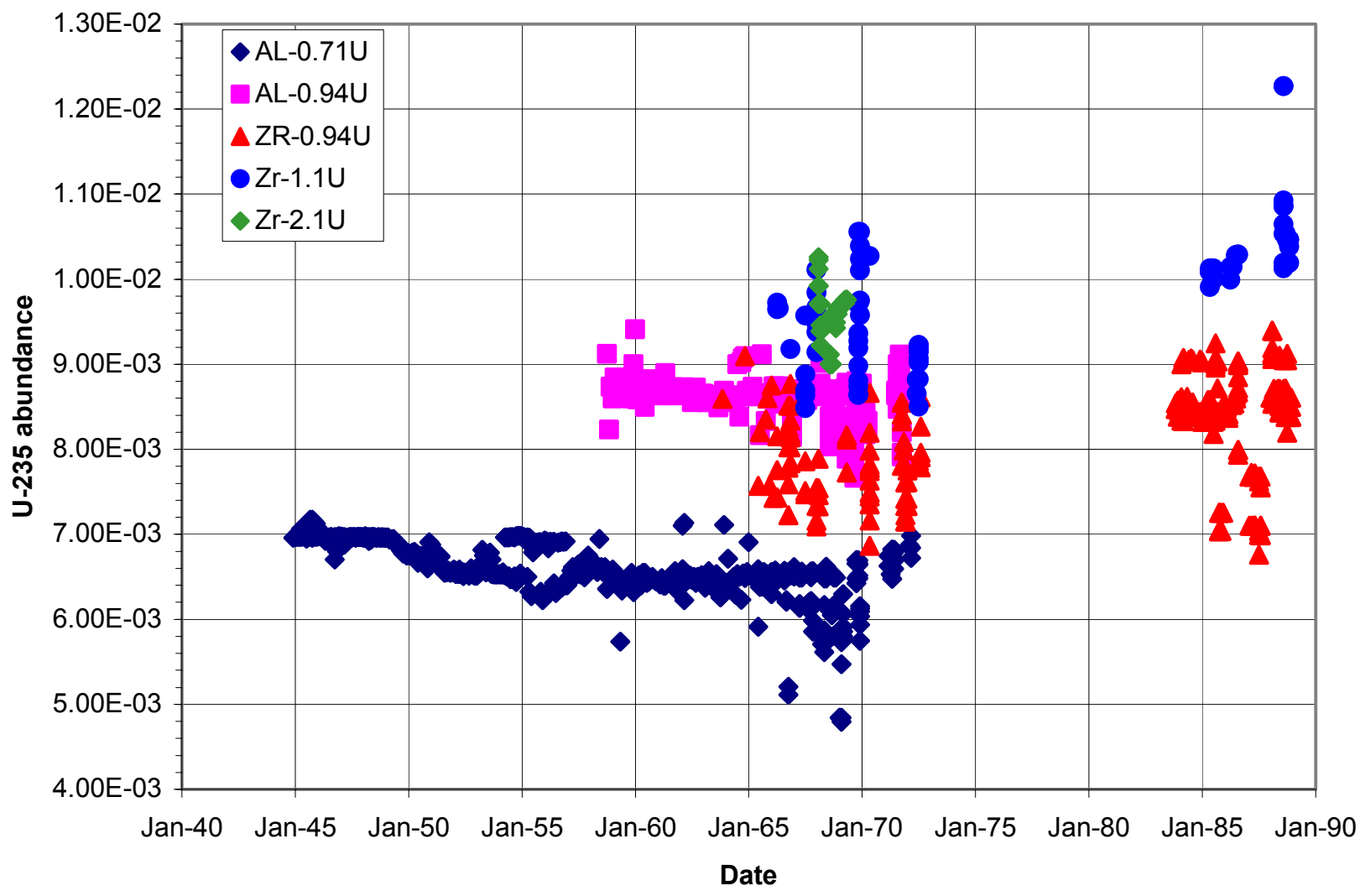

Figure 1.2. Uranium-235 Abundance for Hanford Reactor Fuel. See Table 1.1 for description of fuel types.

The isotopic abundance of uranium-236 calculated by OREGEN2/DKPRO for each fuel load is shown in Figure 1.3. There is very good separation of the uranium-236 abundance between the AL-0.71U, single-pass reactor fuel and the enriched fuels. The Zircaloy clad fuel shows a large scatter in the uranium-236. Although the Zircaloy overlaps the AL-0.94U fuel, the uranium-236 increases with increasing burnup while uranium- 235 decreases. It should be possible to distinguish the fuel types by plotting uranium-236 abundance versus uranium-235 abundance, provided the measurements can be made with sufficient precision and that little mixing has occurred (Figure 1.4). 


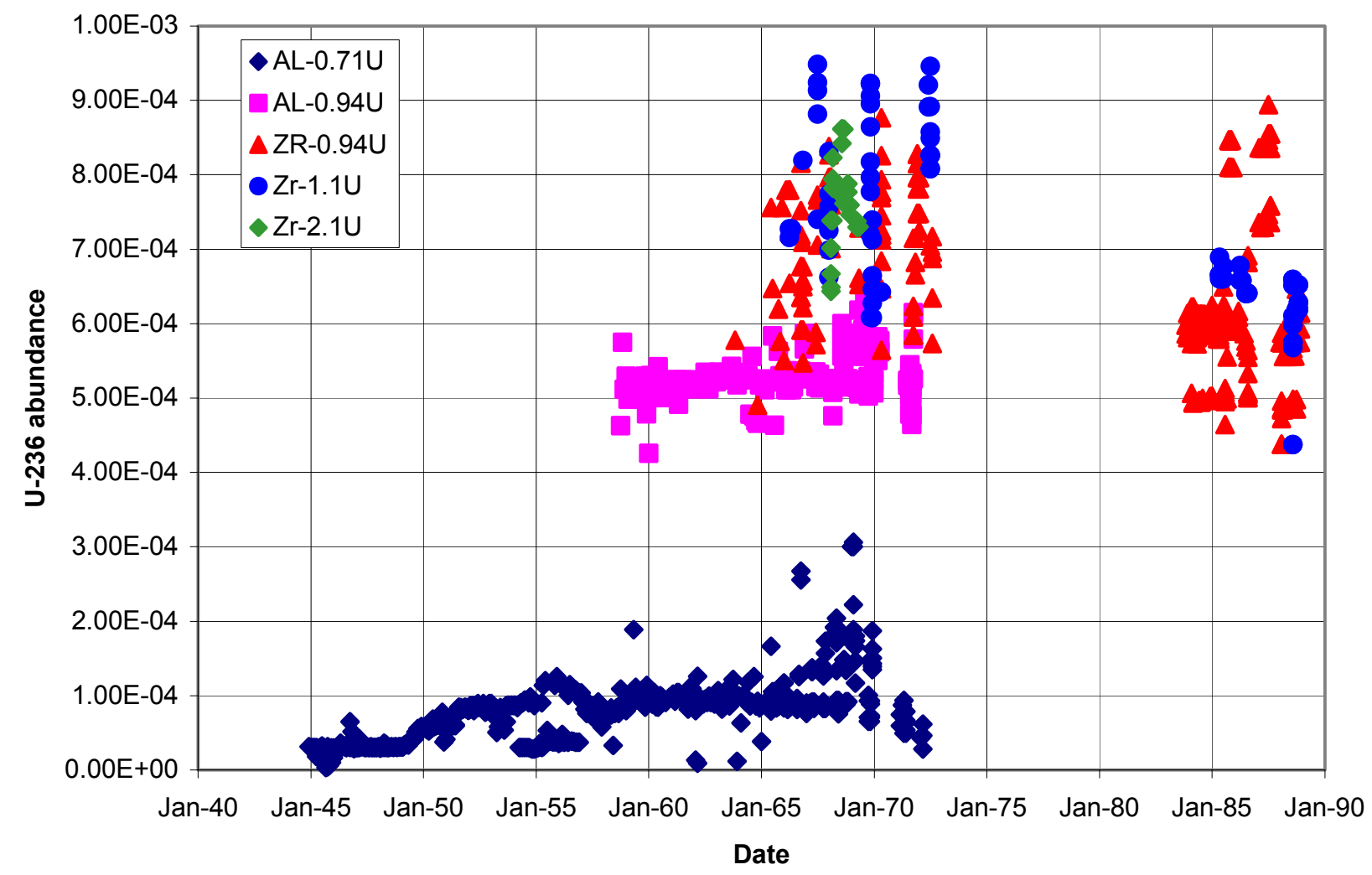

Figure 1.3. Uranium-236 Abundance for Hanford Reactor Fuel. See Table 1.1 for description of fuel types.

The earliest production runs at Hanford had short irradiation times, which resulted in low plutonium240 content. Subsequently, reactor conditions and irradiation times were varied to optimize production. It appears that plutonium of varying purity was produced to meet different objectives (Gumprecht 1954). In general, the plutonium- 240 content increased from the early production of less than $3 \%$ to levels around $6 \%$. Thus, plutonium isotopic composition may provide information on waste history. However, plutonium is generally relatively immobile in groundwater and is seldom detected by conventional analyses of Hanford Site groundwater.

Other plutonium isotopes are potentially of interest in providing signatures. These include plutonium-238, -241, and -242. Only low levels of plutonium-238 were produced during the production runs. Plutonium-241 is of particular interest because its short half-life can help age date contamination, provided initial composition is known or can be inferred. After plutonium-239 and -240, plutonium-241 is of greatest interest in determining plutonium sources and transport history. However, detection of environmental levels of plutonium-241 currently requires expensive thermal-ionization massspectrometry (TIMS) and was not pursued as part of this study. Plutonium-242 levels also are very low and can generally be discounted in environmental studies. Plutonium-242 and -244 are commonly used as tracers in analytical methods. 


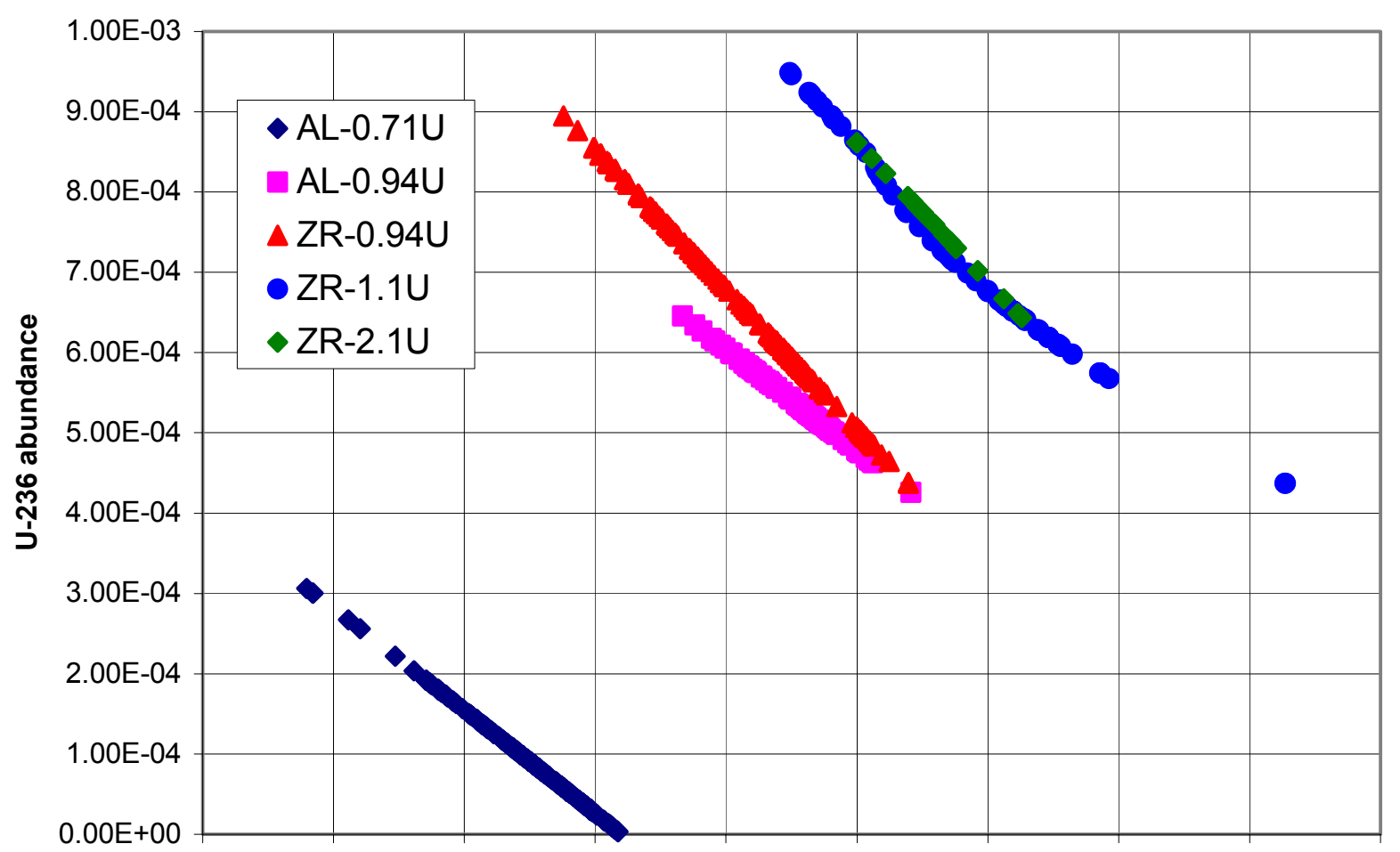

4.00E-03 5.00E-03 6.00E-03 7.00E-03 8.00E-03 9.00E-03 1.00E-02 1.10E-02 1.20E-02 1.30E-02

\section{U-235 abundance}

Figure 1.4. Uranium-236 versus Uranium-235 Abundance for Hanford Reactor Fuel. See Table 1.1 for description of fuel types.

Nuclear reactors produce a wide variety of fission products. The fission products under reactor conditions are typically asymmetrical - the two particles tend to have different mass. This leads to fission yield curves for uranium-235 and plutonium-239 as shown in Figure 1.5. The vast majority of the fission events produce a pair of nuclei with excess neutrons. This results in unstable atoms. These nuclei generally beta-decay to higher atomic number elements along the same mass isobar. Many moderate to long-lived and stable isotopes are found in fission waste. The isotopes of greatest concern from an environmental risk standpoint are those that are most mobile and are most radioactive over the time scale of interest. Thus, for example ruthenium-106 was of great concern during production at Hanford Site due to its high fission yield and one year half-life. The half-life was long enough to persist through processing and waste disposal but short enough to lead to high decay rates. The ruthenium-106 has, however, essentially decayed away since shutdown of the reactors and long-lived mobile isotopes, such as technetium-99, are becoming most important.

The wide variety of fission products produces a number of built-in tracers for waste material. A number of stable isotopes and long-lived isotopes can be used, in theory, to identify waste sources and transport, but most have not been well studied. Technetium-99 is highly mobile in oxidizing groundwater and is one of the more significant risks. The groundwater project commonly measures technetium-99 by 


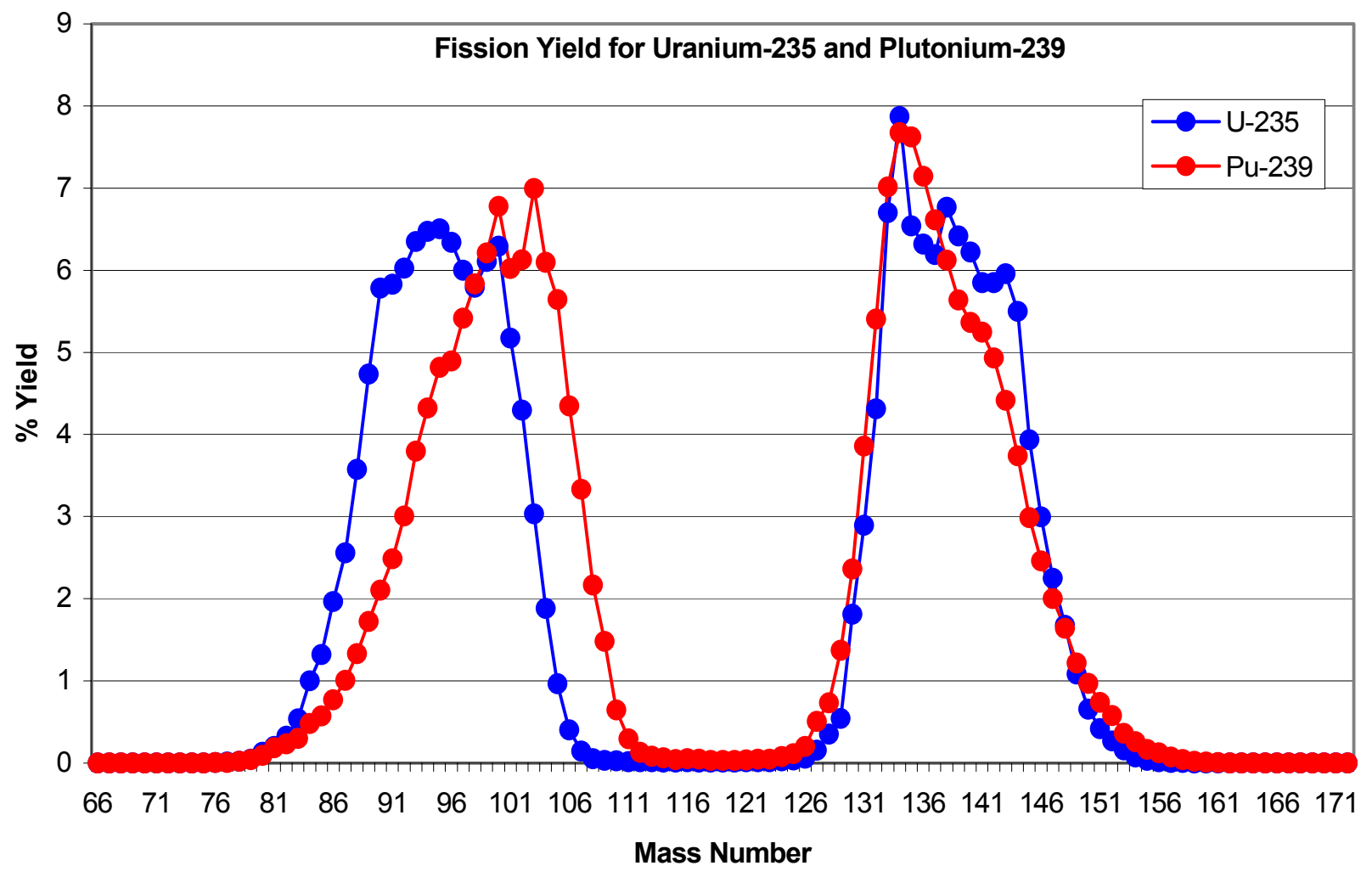

Figure 1.5. Fission Yield Curves for Uranium-235 and Plutonium-239

radiometric methods, but ICP-MS methods recently have been developed. Selenium isotopes also are of interest, in particular selenium-79, which has a long half life (6.5e5 years) and may be a driver in longterm risk calculations. In addition, stable isotopes of molybdenum, ruthenium, and rhodium are produced by fission and are expected to be mobile in groundwater.

Activation products are found in addition to fission products in Hanford Site waste streams. Activation products are formed by neutron capture or $n-2 n$ reactions on a variety of materials or trace impurities in the reactors. Cobalt- 60 is an activation product that has been of particular interest due to its potential contribution to radiation dose. Cobalt- 60 has been detected in Hanford Site groundwater and a fraction of the cobalt is, in some instances, mobilized as anionic or neutral complexes. However, cobalt-60 is not a contributor to long-term risk because the 5.27 year half life means that it will decay to insignificant levels. Chlorine-36 is a long-lived radionuclide (3.01e 5 years) that is produced by activation of traces of chlorine-35. Chlorine-36 is highly mobile in the environment and may be a contributor to long-term risk in some circumstances. However, the long half life, low energy of the beta emission, and low potential for bioaccumulation minimize the risk. Additional activation products of interest include nickel-59 and nickel-63. Nickel-59 has a very long half life of 7.64e 4 years, while the half life of nickel-63 is 100 years. Very low levels of nickel-63 have been detected in Hanford Site groundwater, but it is not expected to be highly mobile. Other activation products such as aluminum-26, niobium-94, cadmium110 and tungsten-183 are probably of more interest in vadose zone or source area studies due to limited mobility. 


\subsection{Sampling}

Groundwater sampling was performed according to standard protocols employed for routine monitoring onsite. Wells were generally purged until temperature, specific conductance, and $\mathrm{pH}$ stabilized and for at least 3 bore volumes. Some large volume wells with lower capacity pumps were purged for only 1 hour, producing less than 3 bore volumes. The sampling goal is to sample after turbidity drops below 5 NTU, but this is not possible in all cases. Generally turbidity was below 20 NTU. In the initial study, filtered, unfiltered, acidified, and non-acidified samples were collected. The early study determined that filtered and nitric acid acidified samples were the most useful for determining uranium concentrations in groundwater. Plutonium isotopes were measured on unfiltered, non-acidified samples because of the linkage with the colloidal transport study. Those samples were collected with low-flow sampling techniques (using a bladder pump at 100 to $200 \mathrm{ml} / \mathrm{min}$ flow). The low-flow technique minimized the introduction of settleable particles into the samples. 


\subsection{Analytical Methods}

This section briefly describes the analytical methods employed for uranium isotopes and total uranium, plutonium isotopes, and the fission products ruthenium and molybdenum. All ICP-MS analyses were performed on a Varian quadrapole ICP-MS. The chlorine-36 method used at Lawrence Livermore National Laboratory is also summarized.

\subsection{Uranium}

Uranium is separated from matrix elements in groundwater samples prior to determination of uranium-234, $-235,-236$, and -238 isotopic ratios and total uranium. The natural uranium concentration obtained in the procedure blank and reagents and/or ion-exchange resin impurities defines the detection limit for uranium isotopes.

The unknown sample is first screened for total uranium concentration. After determining the total uranium as uranium-238, an aliquot of sample is processed to produce $10 \mathrm{~mL}$ of $1 \mathrm{ng} / \mathrm{mL}$ total uranium. All sample solutions, blanks, check samples, and other quality control (QC) samples are spiked with uranium-233 tracer at a concentration of $1 \mathrm{ng} / \mathrm{mL}$. The method detection level is approximately $5 \mathrm{fg} / \mathrm{mL}$ $(0.000005 \mu \mathrm{g} / \mathrm{L})$ for the minor isotopes of uranium in weak oxalic acid. The sample detection limit for individual isotopes is sample-specific because the sample aliquot is based on the total uranium concentration.

The aliquot of sample, acidified with nitric acid is separated from the matrix by loading the uranium fraction onto 20 to 50 micron-sized Eichrome ${ }^{\circledR}$ TRU resin FPS. The uranium is then stripped from the column using $10 \mathrm{~mL}$ of $0.05-\mathrm{M}$ oxalic acid. The oxalic acid solution is injected into the ICP-MS and isotopic ratios of mass units 233, 234, 235, 236, and 238 measured. Sample measurements are first corrected for background counts, a blank subtraction is applied and an alpha correction based on the mass response of a known standard is calculated. Concentrations of individual isotopes are calculated by comparison of the isotope response in the sample to the uranium-233 internal standard. The total uranium is the sum of the individual isotope concentrations.

\subsection{Plutonium}

For plutonium analysis, $500 \mathrm{fg}$ of plutonium-242 tracer and $5 \mathrm{mg}$ iron nitrate precipitating agent are added to $100 \mathrm{~mL}$ of sample solution. Seven $\mathrm{mL}$ of concentrated nitric acid is added to acidify the solution to 1 molar nitric acid. The sample is placed on a hot plate, brought to a boil, and then removed from the heat. The sample solution is then precipitated using $\mathrm{NH}_{4} \mathrm{OH}$ and allowed to cool to support complete precipitation of most metals. The precipitate is then filtered and washed with weak $\mathrm{NH}_{4} \mathrm{OH}$ and transferred to a Teflon beaker. The precipitate is then redissolved with $2 \mathrm{~mL}$ of $2.5 \mathrm{M} \mathrm{HNO}_{3}$. This solution is then injected into a $150 \mu \mathrm{L}$ TEVA column on-line to the ICP-MS. The loading process is done using $2 \mathrm{M}$ nitric acid diverted out to waste where most metals are eluted, including the uranium isotopes. The 
plutonium isotopes are then striped from the column using a weak $(0.005 \mathrm{M})$ nitric acid and $0.05 \mathrm{M}$ oxalic acid. The transient plutonium response is measured by the on-line ICP-MS.

Americium-241 may be quantified through a modification of this procedure but has not been included in the current work. Neptunium-237 also may be detected, but it cannot be quantified accurately because no tracer is available to determine the yield in the chemical separation.

\subsection{Molybdenum and Ruthenium}

Molybdenum and ruthenium isotopes are separated from matrix elements using a Dowex ${ }^{\circledR}$ 50X8 cation resin prior to measurement by ICP-MS. Other isotopes that can be measured using this procedure include technetium-99, rhodium-103, and palladium-105. Those isotopes were not a focus for this study so the results for those isotopes will be discussed separately. The samples are first screened for molybdenum concentration and an aliquot chosen to give approximately $40 \mathrm{ng}$ in the final $10 \mathrm{ml}$ solution. Indium-115 is used as an internal standard. The sample is placed in a $0.15 \mathrm{M} \mathrm{HNO}_{3}$ matrix and loaded onto the anion resin column. The molybdenum and ruthenium (as well as technetium, rhodium, and palladium) pass through the resin as oxyanions. Corrections are made for background counts and blank concentrations. Standards of natural abundance ruthenium and molybdenum are used to calculate alpha corrections (mass response correction) and for quantification of concentrations.

Molybdenum-92, $-94,-95,-96,-97,-98$, and -100 are measured. The presence of natural ruthenium could interfere with the measurement of molybdenum-96, -98, and -100, but examination of the other ruthenium and molybdenum isotopes generally shows that this is insignificant. Where measurement of ruthenium-101, -102, and -104 ratios indicates the presence of natural ruthenium, then the impact on molybdenum measurements needs to be considered. A more serious problem is interference from zirconium. Zirconium-92, -94, and -96 will interfere with those molybdenum isotopes. Most of the zirconium is separated using the anion resin; however, it remains as a trace contaminant even after the sample preparation. Residual zirconium in the sample must be subtracted to correct the isobaric interference on molybdenum isotopes. Alternatively, the relative atomic ratio of molybdenum-95, -97, -98, and -100 can be examined to evaluate relative contributions from fission and natural abundance molybdenum while avoiding uncertainties introduced by the zirconium correction.

Ruthenium-101, -102, and -104 are measured. Natural palladium is an unlikely interference on ruthenium-102 and -104, only. The palladium isobaric interference can generally be discounted unless the mass-104 abundance is much greater than the mass-102 abundance because the natural palladium-104 abundance is approximately 11 times the palladium-102 abundance. Since only selected ruthenium isotopes are quantified, the alpha correction is based on the natural ratio between those isotopes rather than the total isotopic abundance.

The molybdenum concentrations for the groundwater samples discussed in this report were not quantified directly due to a problem with the molybdenum standard. The isotope ratios are calculated independently of the absolute concentrations and, thus, are unaffected. 
Technetium-99, rhodium-103, and palladium-105 also may be determined in solutions that have been prepared for analysis of molybdenum and ruthenium isotopes, as discussed above. For this study, technetium-99, rhodium-103, and palladium-105 were measured but were not quantified against standards. The blank-subtracted counts for each of these are proportional to the isotopic concentration, however. Thus, the isotopic abundances can be compared to ruthenium and molybdenum, based on the relative count rates.

\subsection{Chlorine-36}

Chlorine-36 was measured in groundwater samples by accelerator mass spectrometry. Sample preparation and analysis was performed at Lawrence Livermore National Laboratory Center for Accelerator Mass Spectrometry. The chloride is precipitated from solution as silver chloride. Chlorine-36 free silver chloride is used as a carrier to dilute the samples to the range of the instrument. The sample is introduced into a tandem Van deGraaf linear accelerator and the chlorine-36 to total chloride ratio is measured. Chloride analyses performed on splits of the groundwater samples are used to quantify the chlorine-36 concentration in the samples. 


\subsection{Results}

The isotopic signature investigation has provided information about several issues of concern to the Hanford Groundwater Monitoring Project. Uranium isotopic results have been obtained from a variety of locations across the site and the results indicate several uranium sources. The uranium types identified include natural uranium, enriched uranium, depleted uranium, and uranium waste from irradiated Hanford fuel. Fewer measurements have been made on plutonium isotopes, but the results indicate that the signature near the 216-B-5 injection well are consistent with early Hanford fuel. Most groundwater measurements on molybdenum and ruthenium isotopes thus far are from samples collected near the BY cribs and the B-BX-BY tank farms. These clearly show the presence of fission-product ruthenium, but fission molybdenum appears to be absent. This is in contrast to vadose contamination samples from the SX tank farm where results show the presence of fission molybdenum but no fission ruthenium. One groundwater sample collected near T Plant shows a ruthenium isotopic signature that is close to that of natural ruthenium. The results are presented and discussed in further detail in this section.

\subsection{Uranium}

The uranium isotopic concentrations for samples analyzed in this study are shown in Table 4.1. The isotopic abundance is reported in Table 4.2. These data include the initial samples used for method development in 1999 and samples collected in 2001. All isotopes except for uranium-236 were detectable in all samples.

Total uranium concentrations in the samples ranged from less than $1 \mu \mathrm{g} / \mathrm{L}$ to $524 \mu \mathrm{g} / \mathrm{L}$. At low concentrations, most samples show enrichment with uranium-234 relative to the natural isotopic abundance whereas the uranium-235 remains near the natural abundance (Figure 4.1). The enrichment with uranium-234 is believed to be the result of the alpha-recoil effect (Osmond and Cowart 1976; Fleischer 1980). This is where the alpha decay of uranium-238 in minerals and subsequent beta decay to uranium234 strains the crystal lattice, leading to preferential leaching of uranium-234 relative to uranium-238, which remains in unstrained sites. At higher concentrations, the samples show slight depletion of uranium-235. The depletion appears to be due to burn-up of uranium fuel in the Hanford reactors.

Two samples plot far from the trend of the other samples. The first of these samples is from well 699-S31-E10B, which is located in the southern part of the site, downgradient from an off-site commercial fuel fabrication facility. The uranium in this sample is enriched in both uranium-235 and uranium-234. The isotopic enrichment to a uranium-235 abundance of 0.0195 suggests that the fuel fabrication is a source of uranium in groundwater at this location. The second sample is from well 699-S6-E4A which is located next to the 316-4 crib (near the 618-10 burial ground). This crib received waste from the 300 Area research activities. The uranium in this well is depleted in uranium-234 and uranium-235. This is consistent with 300 Area research activities, which were performed on a variety of uranium compositions, including depleted uranium. 
Table 4.1. Uranium Isotopic Concentrations in Samples from the Hanford Site

\begin{tabular}{|c|c|c|c|c|c|c|c|}
\hline Well & Sample & Date & $\begin{array}{l}\mathrm{U}-234 \\
\mu \mathrm{g} / \mathrm{L}\end{array}$ & $\begin{array}{l}\mathrm{U}-235 \\
\mu \mathrm{g} / \mathrm{L}\end{array}$ & $\begin{array}{l}\mathrm{U}-236 \\
\mu \mathrm{g} / \mathrm{L}\end{array}$ & $\begin{array}{l}\mathrm{U}-238 \\
\mu \mathrm{g} / \mathrm{L}\end{array}$ & $\begin{array}{c}\text { Total U } \\
\mu \mathrm{g} / \mathrm{L}\end{array}$ \\
\hline $\begin{array}{l}\text { Drive Point by } \\
\text { Well } 30-47-18 \mathrm{~B}\end{array}$ & B0WD53 & 09/30/99 & 0.000120 & 0.014 & N.D. & 1.931 & 1.95 \\
\hline 1199-39-16D & B0WCY9 & $09 / 26 / 99$ & 0.000022 & 0.002 & 0.000004 & 0.305 & 0.31 \\
\hline 1199-39-16D & B0WD00 & 09/26/99 & 0.000024 & 0.002 & 0.000004 & 0.315 & 0.32 \\
\hline 199-K-109A & B0TRN5 & $03 / 01 / 99$ & 0.000556 & 0.060 & 0.003723 & 8.427 & 8.49 \\
\hline 199-K-27 & B0TR78 & $03 / 10 / 99$ & 0.000360 & 0.040 & 0.000930 & 5.537 & 5.58 \\
\hline $199-K-30$ & B0TR82 b & $03 / 01 / 99$ & 0.000307 & 0.037 & N.D. & 5.108 & 5.15 \\
\hline 299-E28-18 & B11VB5 & $05 / 14 / 01$ & 0.001526 & 0.202 & 0.001461 & 29.519 & 29.72 \\
\hline 299-E28-2 & B0W424 & 08/08/99 & 0.000280 & 0.033 & 0.000162 & 4.747 & 4.78 \\
\hline 299-E28-25 & B0W446 & $08 / 11 / 99$ & 0.000384 & 0.046 & 0.000186 & 6.601 & 6.65 \\
\hline 299-E33-13 & B0TR86 & $02 / 24 / 99$ & 0.003364 & 0.433 & 0.004477 & 62.932 & 63.37 \\
\hline 299-E33-16 & B11VB0 & $05 / 04 / 01$ & 0.000841 & 0.099 & 0.000598 & 14.364 & 14.46 \\
\hline 299-E33-18 & B0TR90 & $02 / 25 / 99$ & 0.006248 & 0.782 & 0.008434 & 114.190 & 114.99 \\
\hline 299-E33-18 & B11VB2 & $05 / 04 / 01$ & 0.006502 & 0.813 & 0.009306 & 121.883 & 122.70 \\
\hline 299-E33-26 & B11VB1 & $05 / 10 / 01$ & 0.005056 & 0.616 & 0.006667 & 92.217 & 92.84 \\
\hline 299-E33-38 & B11VB3 & $05 / 09 / 01$ & 0.006651 & 0.788 & 0.008574 & 117.600 & 118.40 \\
\hline 299-E33-38 & B11VB4 & $05 / 09 / 01$ & 0.006907 & 0.797 & 0.008811 & 118.863 & 119.70 \\
\hline 299-E33-41 & B0TRP0 & $03 / 01 / 99$ & 0.001124 & 0.136 & 0.001342 & 20.093 & 20.23 \\
\hline 299-E33-42 & B0TR98 & $02 / 25 / 99$ & 0.000548 & 0.065 & 0.000488 & 9.453 & 9.52 \\
\hline 299-E33-44 & B11VB6 & $05 / 04 / 01$ & 0.021613 & 2.750 & 0.030546 & 408.880 & 411.70 \\
\hline 299-E33-5 & B0TRB2 & $02 / 24 / 99$ & 0.003743 & 0.466 & 0.004980 & 70.356 & 70.83 \\
\hline 299-E33-7 & B0TRB6 & $02 / 24 / 99$ & 0.000213 & 0.025 & N.D. & 3.432 & 3.46 \\
\hline 299-E33-9 & B11V99 & $05 / 16 / 01$ & 0.027331 & 3.462 & 0.039816 & 520.315 & 523.80 \\
\hline 299-W10-1 & B0VC15 & $05 / 06 / 99$ & 0.000109 & 0.009 & N.D. & 1.209 & 1.22 \\
\hline 299-W10-24 & B0TRC0 & $03 / 02 / 99$ & 0.000137 & 0.013 & 0.000060 & 1.881 & 1.90 \\
\hline 299-W11-14 & B11VB7 & $05 / 14 / 01$ & 0.002881 & 0.343 & 0.001977 & 49.544 & 49.89 \\
\hline 299-W11-23 & B0TRC8 & $03 / 04 / 99$ & 0.000193 & 0.016 & N.D. & 2.115 & 2.13 \\
\hline 299-W14-14 & B0TRD6 & $03 / 03 / 99$ & 0.000091 & 0.008 & N.D. & 1.185 & 1.19 \\
\hline 299-W22-46 & B0TRF0 & $03 / 03 / 99$ & 0.000309 & 0.037 & 0.000266 & 5.369 & 5.41 \\
\hline 299-W23-15 & B0TRF4 & $03 / 04 / 99$ & 0.000716 & 0.088 & 0.001148 & 13.154 & 13.24 \\
\hline 699-50-53A & B0TYT7 & $04 / 28 / 99$ & 0.000271 & 0.030 & N.D. & 4.188 & 4.22 \\
\hline 699-S29-E16A & B0WD25 & $09 / 22 / 99$ & 0.000238 & 0.028 & N.D. & 4.001 & 4.03 \\
\hline 699-S31-E10B & B11VB8 & $05 / 15 / 01$ & 0.002091 & 0.241 & 0.000556 & 12.280 & 12.52 \\
\hline 699-S37-E14 & B0WD39 & $09 / 20 / 99$ & 0.000120 & 0.013 & N.D. & 1.920 & 1.93 \\
\hline 699-S43-E12 & B0WCY3 & $09 / 24 / 99$ & 0.000312 & 0.036 & N.D. & 5.040 & 5.08 \\
\hline 699-S6-E4A & B0TM08 & $01 / 25 / 99$ & 0.003272 & 0.516 & 0.001344 & 98.333 & 98.85 \\
\hline
\end{tabular}


Table 4.2. Uranium Isotopic Abundance in Samples from the Hanford Site

\begin{tabular}{|c|c|c|c|c|c|c|c|}
\hline Sample & Well & $\begin{array}{l}\text { Sample } \\
\text { Date }\end{array}$ & $\begin{array}{c}\text { Total U } \\
\mu \mathrm{g} / \mathrm{L}\end{array}$ & $\begin{array}{c}\text { U-234 } \\
\text { Abundance }\end{array}$ & $\begin{array}{c}\mathrm{U}-235 \\
\text { Abundance }\end{array}$ & $\begin{array}{c}\text { U-236 } \\
\text { Abundance }\end{array}$ & $\begin{array}{c}\text { U-238 } \\
\text { Abundance }\end{array}$ \\
\hline & $\begin{array}{l}\text { Natural } \\
\text { Abundance }\end{array}$ & & & $5.50 \mathrm{E}-05$ & $7.20 \mathrm{E}-03$ & $0.00 E+00$ & 9.93E-01 \\
\hline B0WD53 & $\begin{array}{l}\text { Drive Point by } \\
\text { Well } 30-47-18 \mathrm{~B}\end{array}$ & 09/30/99 & 1.95 & $6.27 \mathrm{E}-05$ & 7.37E-03 & N.D. & 9.93E-01 \\
\hline B0WCY9 & 1199-39-16D & $09 / 26 / 99$ & 0.31 & $7.38 \mathrm{E}-05$ & $6.97 \mathrm{E}-03$ & $1.24 \mathrm{E}-05$ & $9.93 \mathrm{E}-01$ \\
\hline B0WD00 & 1199-39-16D & $09 / 26 / 99$ & 0.32 & 7.59E-05 & $6.98 \mathrm{E}-03$ & $1.41 \mathrm{E}-05$ & $9.93 \mathrm{E}-01$ \\
\hline B0TRN5 & 199-K-109A & 03/01/99 & 8.49 & $6.66 \mathrm{E}-05$ & $7.20 \mathrm{E}-03$ & $4.42 \mathrm{E}-04$ & $9.92 \mathrm{E}-01$ \\
\hline B0TR78 & 199-K-27 & 03/10/99 & 5.58 & $6.54 \mathrm{E}-05$ & 7.24E-03 & $1.68 \mathrm{E}-04$ & 9.93E-01 \\
\hline B0TR82 & $199-K-30$ & 03/01/99 & 5.15 & $6.08 \mathrm{E}-05$ & 7.33E-03 & N.D. & $9.93 \mathrm{E}-01$ \\
\hline B11VB5 & 299-E28-18 & $05 / 14 / 01$ & 29.72 & $5.20 \mathrm{E}-05$ & $6.87 \mathrm{E}-03$ & $5.00 \mathrm{E}-05$ & $9.93 \mathrm{E}-01$ \\
\hline B0W424 & 299-E28-2 & 08/08/99 & 4.78 & $5.97 \mathrm{E}-05$ & 7.03E-03 & $3.41 \mathrm{E}-05$ & 9.93E-01 \\
\hline B0W446 & 299-E28-25 & $08 / 11 / 99$ & 6.65 & $5.88 \mathrm{E}-05$ & $7.08 \mathrm{E}-03$ & $2.82 \mathrm{E}-05$ & $9.93 \mathrm{E}-01$ \\
\hline B0TR86 & 299-E33-13 & $02 / 24 / 99$ & 63.37 & $5.40 \mathrm{E}-05$ & $6.91 \mathrm{E}-03$ & $7.13 \mathrm{E}-05$ & 9.93E-01 \\
\hline $\mathrm{B} 11 \mathrm{VB} 0$ & 299-E33-16 & $05 / 04 / 01$ & 14.46 & $5.90 \mathrm{E}-05$ & $6.96 \mathrm{E}-03$ & $4.20 \mathrm{E}-05$ & $9.93 \mathrm{E}-01$ \\
\hline B0TR90 & 299-E33-18 & $02 / 25 / 99$ & 114.99 & $5.53 \mathrm{E}-05$ & $6.89 \mathrm{E}-03$ & $7.40 \mathrm{E}-05$ & $9.93 \mathrm{E}-01$ \\
\hline $\mathrm{B} 11 \mathrm{VB} 2$ & 299-E33-18 & $05 / 04 / 01$ & 122.70 & $5.40 \mathrm{E}-05$ & $6.71 \mathrm{E}-03$ & $7.60 \mathrm{E}-05$ & $9.93 \mathrm{E}-01$ \\
\hline B11VB1 & 299-E33-26 & $05 / 10 / 01$ & 92.84 & $5.50 \mathrm{E}-05$ & $6.72 \mathrm{E}-03$ & $7.20 \mathrm{E}-05$ & $9.93 \mathrm{E}-01$ \\
\hline B11VB3 & 299-E33-38 & $05 / 09 / 01$ & 118.40 & $5.70 \mathrm{E}-05$ & $6.74 \mathrm{E}-03$ & 7.30E-05 & 9.93E-01 \\
\hline B11VB4 & 299-E33-38 & $05 / 09 / 01$ & 119.70 & $5.90 \mathrm{E}-05$ & $6.74 \mathrm{E}-03$ & 7.40E-05 & 9.93E-01 \\
\hline B0TRP0 & 299-E33-41 & $03 / 01 / 99$ & 20.23 & $5.65 \mathrm{E}-05$ & $6.79 \mathrm{E}-03$ & $6.69 \mathrm{E}-05$ & $9.93 \mathrm{E}-01$ \\
\hline B0TR98 & 299-E33-42 & $02 / 25 / 99$ & 9.52 & $5.86 \mathrm{E}-05$ & $6.90 \mathrm{E}-03$ & $5.17 \mathrm{E}-05$ & $9.93 \mathrm{E}-01$ \\
\hline B11VB6 & \begin{tabular}{|l|} 
299-E33-44 \\
\end{tabular} & $05 / 04 / 01$ & 411.70 & $5.30 \mathrm{E}-05$ & $6.76 \mathrm{E}-03$ & $7.50 \mathrm{E}-05$ & $9.93 \mathrm{E}-01$ \\
\hline B0TRB2 & 299-E33-5 & $02 / 24 / 99$ & 70.83 & $5.38 \mathrm{E}-05$ & $6.66 \mathrm{E}-03$ & 7.09E-05 & $9.93 \mathrm{E}-01$ \\
\hline B0TRB6 & 299-E33-7 & $02 / 24 / 99$ & 3.46 & $6.28 \mathrm{E}-05$ & $7.23 \mathrm{E}-03$ & N.D. & 9.93E-01 \\
\hline B11V99 & 299-E33-9 & $05 / 16 / 01$ & 523.80 & $5.30 \mathrm{E}-05$ & 6.69E-03 & 7.70E-05 & $9.93 \mathrm{E}-01$ \\
\hline B0VC15 & 299-W10-1 & 05/06/99 & 1.22 & $9.10 \mathrm{E}-05$ & 7.22E-03 & N.D. & $9.93 \mathrm{E}-01$ \\
\hline B0TRC0 & 299-W10-24 & 03/02/99 & 1.90 & $7.36 \mathrm{E}-05$ & $7.08 \mathrm{E}-03$ & $3.19 \mathrm{E}-05$ & 9.93E-01 \\
\hline B11VB7 & 299-W11-14 & $05 / 14 / 01$ & 49.89 & $5.90 \mathrm{E}-05$ & $6.97 \mathrm{E}-03$ & $4.00 \mathrm{E}-05$ & 9.93E-01 \\
\hline B0TRC8 & 299-W11-23 & $03 / 04 / 99$ & 2.13 & $9.21 \mathrm{E}-05$ & $7.38 \mathrm{E}-03$ & N.D. & $9.93 \mathrm{E}-01$ \\
\hline B0TRD6 & 299-W14-14 & $03 / 03 / 99$ & 1.19 & 7.77E-05 & $7.13 \mathrm{E}-03$ & N.D. & 9.93E-01 \\
\hline B0TRF0 & 299-W22-46 & $03 / 03 / 99$ & 5.41 & $5.81 \mathrm{E}-05$ & $6.85 \mathrm{E}-03$ & $4.97 \mathrm{E}-05$ & $9.93 \mathrm{E}-01$ \\
\hline B0TRF4 & 299-W23-15 & 03/04/99 & 13.24 & $5.50 \mathrm{E}-05$ & 6.72E-03 & 8.74E-05 & 9.93E-01 \\
\hline B0TYT7 & 699-50-53A & $04 / 28 / 99$ & 4.22 & $6.54 \mathrm{E}-05$ & 7.31E-03 & N.D. & 9.93E-01 \\
\hline B0WD25 & 699-S29-E16A & $09 / 22 / 99$ & 4.03 & $6.00 \mathrm{E}-05$ & $7.02 \mathrm{E}-03$ & N.D. & 9.93E-01 \\
\hline B11VB8 & 699-S31-E10B & $05 / 15 / 01$ & 12.52 & $1.70 \mathrm{E}-04$ & $1.95 \mathrm{E}-02$ & $4.50 \mathrm{E}-05$ & $9.90 \mathrm{E}-01$ \\
\hline B0WD39 & 699-S37-E14 & 09/20/99 & 1.93 & $6.33 \mathrm{E}-05$ & $7.06 \mathrm{E}-03$ & N.D. & $9.93 \mathrm{E}-01$ \\
\hline B0WCY3 & 699-S43-E12 & $09 / 24 / 99$ & 5.08 & $6.25 \mathrm{E}-05$ & 7.24E-03 & N.D. & $9.93 \mathrm{E}-01$ \\
\hline B0TM08 & 699-S6-E4A & $01 / 25 / 99$ & 98.85 & 3.37E-05 & 5.29E-03 & $1.37 \mathrm{E}-05$ & $9.95 \mathrm{E}-01$ \\
\hline
\end{tabular}




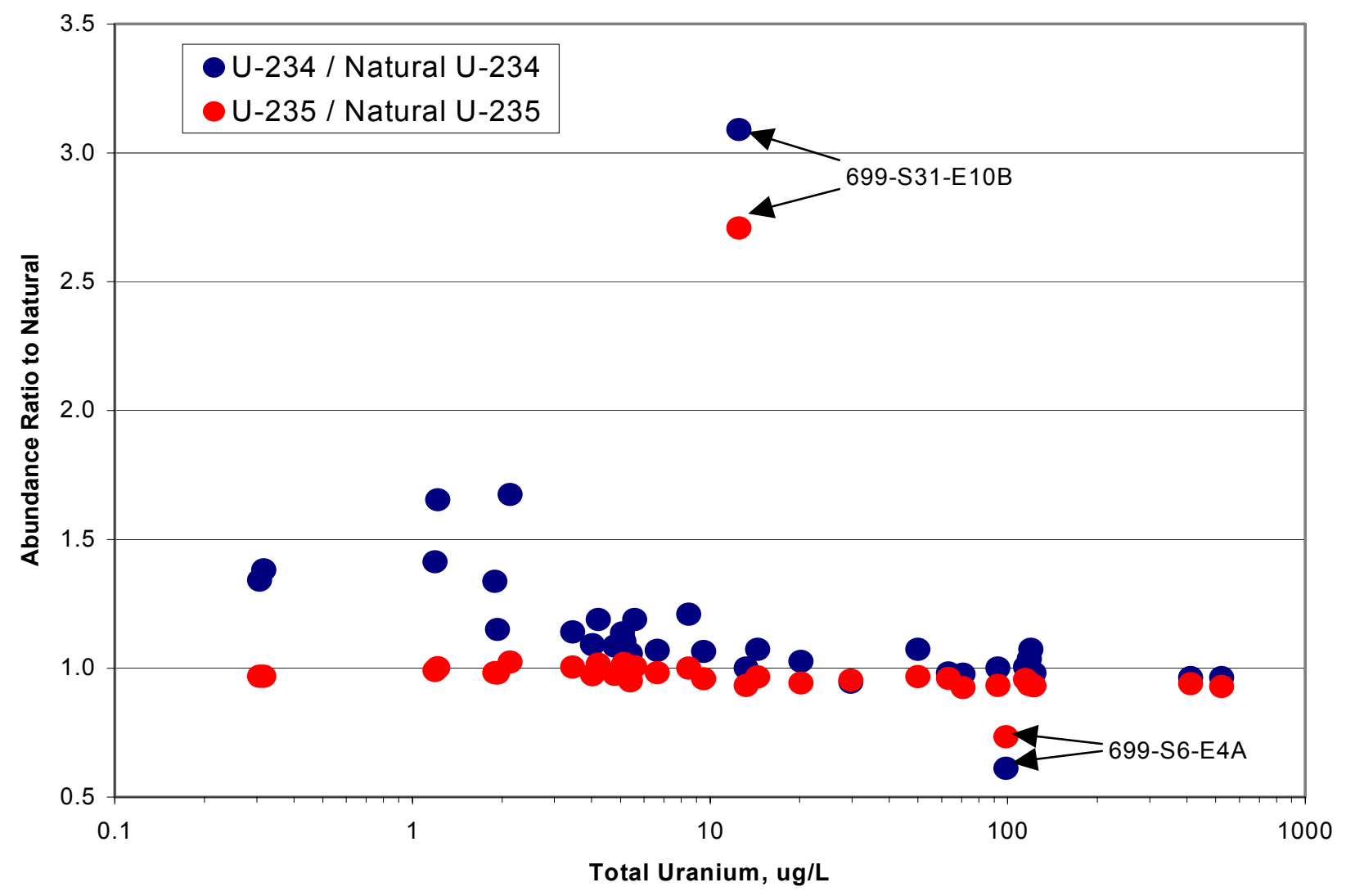

Figure 4.1. Uranium-234 and Uranium-235 Abundance in Groundwater Samples, Normalized to Natural Isotopic Abundance

Most of the uranium samples have uranium-236 and uranium-235 abundance consistent with the unenriched aluminum-clad reactor fuel, AL-0.71U, used in single-pass reactors (Figure 4.2). The high uranium-235 abundance sample from well 699-31-E10B is off-scale on this figure. Background samples with non-detectable uranium-236 also do not plot on this figure. Two samples from $100 \mathrm{~K}$ Area wells 199-K-27 and 199-K-109A plot in positions intermediate between the natural abundance and enriched fuel loads. This suggests that the uranium in these wells is a mixture of different fuel types. The data do not appear sufficient to distinguish between contributions from the aluminum-clad or Zircaloy-clad fuel. It is possible that there was a contribution from Zircaloy fuel in the $100 \mathrm{~K}$ Area since $\mathrm{N}$ reactor fuel is stored in the K East fuel basins, located upgradient from wells 199-K-27 and 199-K-109A.

Sixteen of the samples in this data set come from the vicinity of the B Plant in the 200 East Area. The majority of these are from the vicinity of the BY cribs and B-BX-BY tank farms (Figure 4.3). B Plant operated for plutonium separation from 1945 through 1952 and, thus, only received AL-0.71U fuel from the single-pass reactors. Some of the waste storage and disposal facilities in this area may have received waste from other processing facilities and fuel types, however. Figure 4.4 shows two distinct levels of uranium-236 abundance within the earlier fuel loads. The earliest fuel and some of the fuel processed 


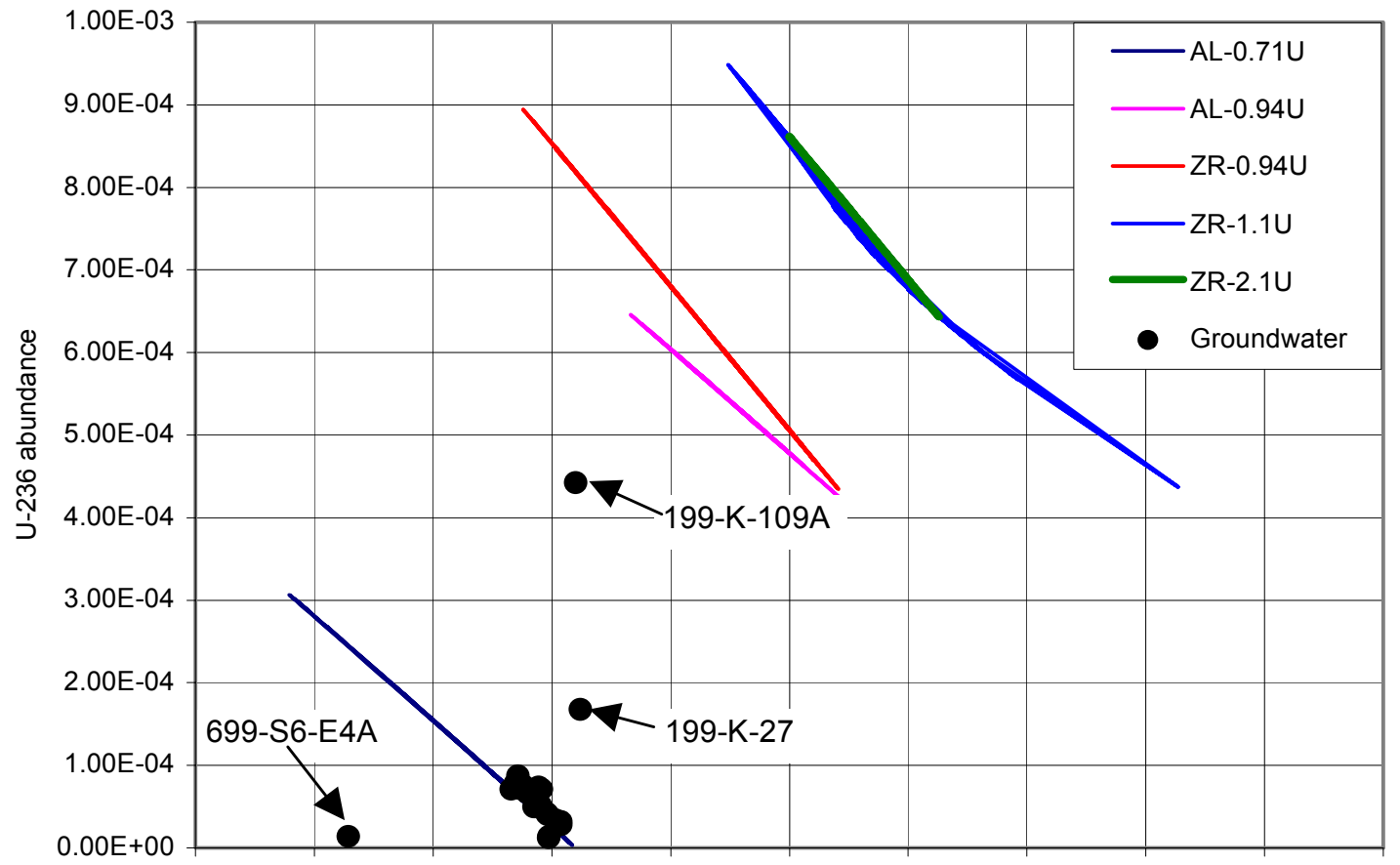

4.00E-03 5.00E-03 6.00E-03 7.00E-03 8.00E-03 9.00E-03 1.00E-02 1.10E-02 1.20E-02 1.30E-02 1.40E-02

$\mathrm{U}-235$ abundance

Figure 4.2. Uranium-236 versus Uranium-235 Abundance for Hanford Groundwater Samples, Compared to Hanford Reactor Fuel. See Table 1.1 for description of fuel types.

between 1954 and 1956 received lower levels of irradiation while most of the fuel was irradiated longer at higher power levels. The highest concentration groundwater samples in the 200 East Area have uranium236 abundance of approximately $7.0 \mathrm{e}-5$ to $7.7 \mathrm{e}-5$. This is consistent with the higher irradiation fuel.

Several of the samples have lower uranium-236 abundance, between approximately 2e-5 and 5e-5. The pre-1950 production shows distinctly lower uranium-236 than most of the later fuel loads as shown in Figure 4.4. During this period, the calculated uranium-236 abundance was generally less than 4e-5. The uranium-236 abundance between 1954 and 1956 was also less than 4e-5 for a portion of the production. This apparently is explained by production of high-purity plutonium-239, which requires shorter irradiation to minimize the plutonium-240. By contrast, the calculated uranium-236 abundance for the rest of the AL-0.71U fuel was typically between $6 \mathrm{e}-5$ and $1.2 \mathrm{e}-4$.

The low abundance uranium-236 samples from the 200 East Area, with the exception of the sample from well 299-E28-18, are consistent with the disposal history for near-by facilities but mixing with natural uranium cannot be ruled out. Mixing with natural uranium will reduce the uranium-236 abundance. At high contaminant concentrations, any effect from natural uranium will be insignificant but it may become a factor at lower concentrations. If natural uranium provides a significant percentage of the total, then uranium-234 should be elevated due to the alpha-recoil effect. The uranium-234 in several of the samples is slightly above natural abundance, but the variability in uranium-234 abundance is similar 


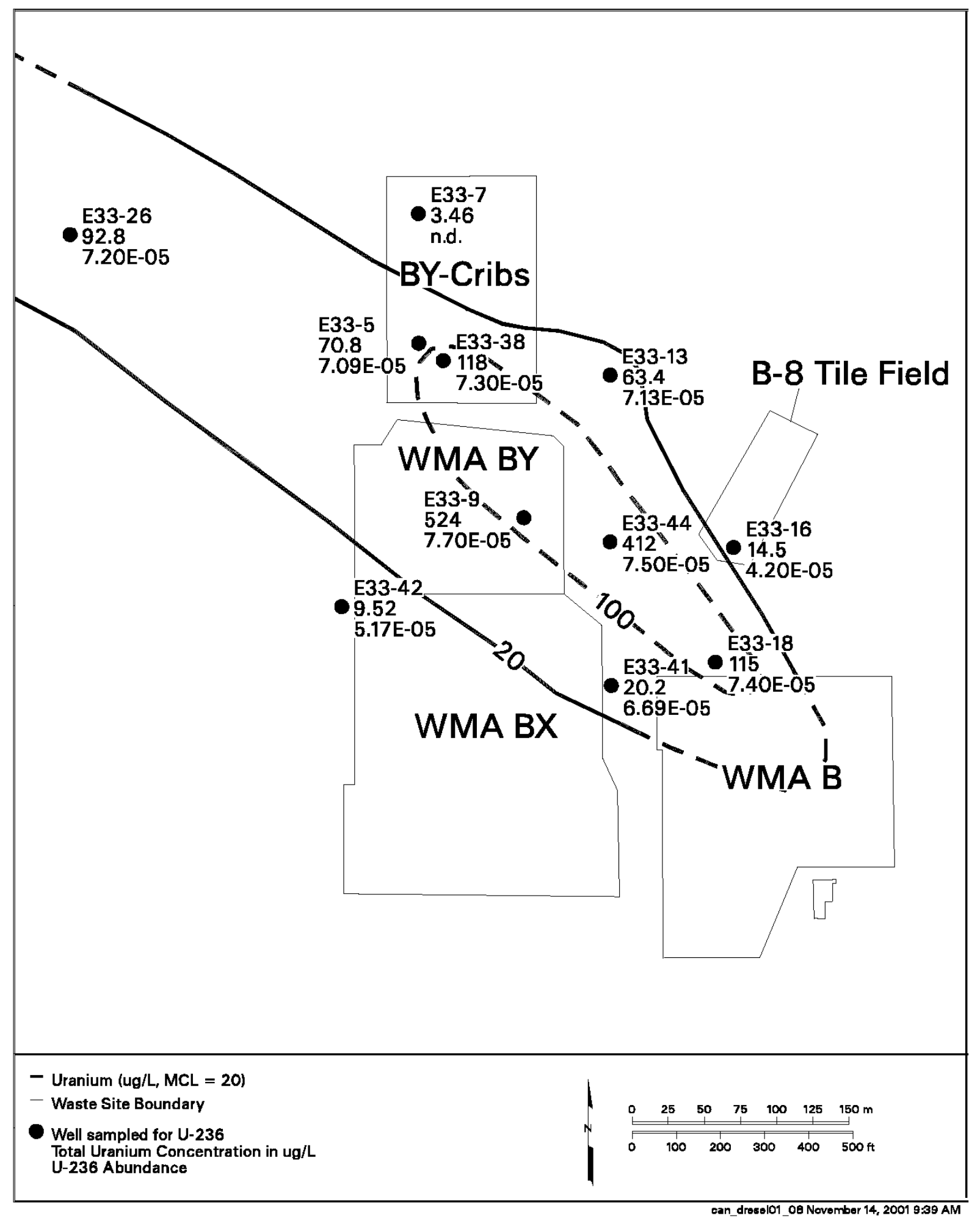

Figure 4.3. Uranium Concentration and Uranium-236 Abundance for Samples from the Vicinity of the BY Cribs and B-BX-BY Tank Farms in the 200 East Area 


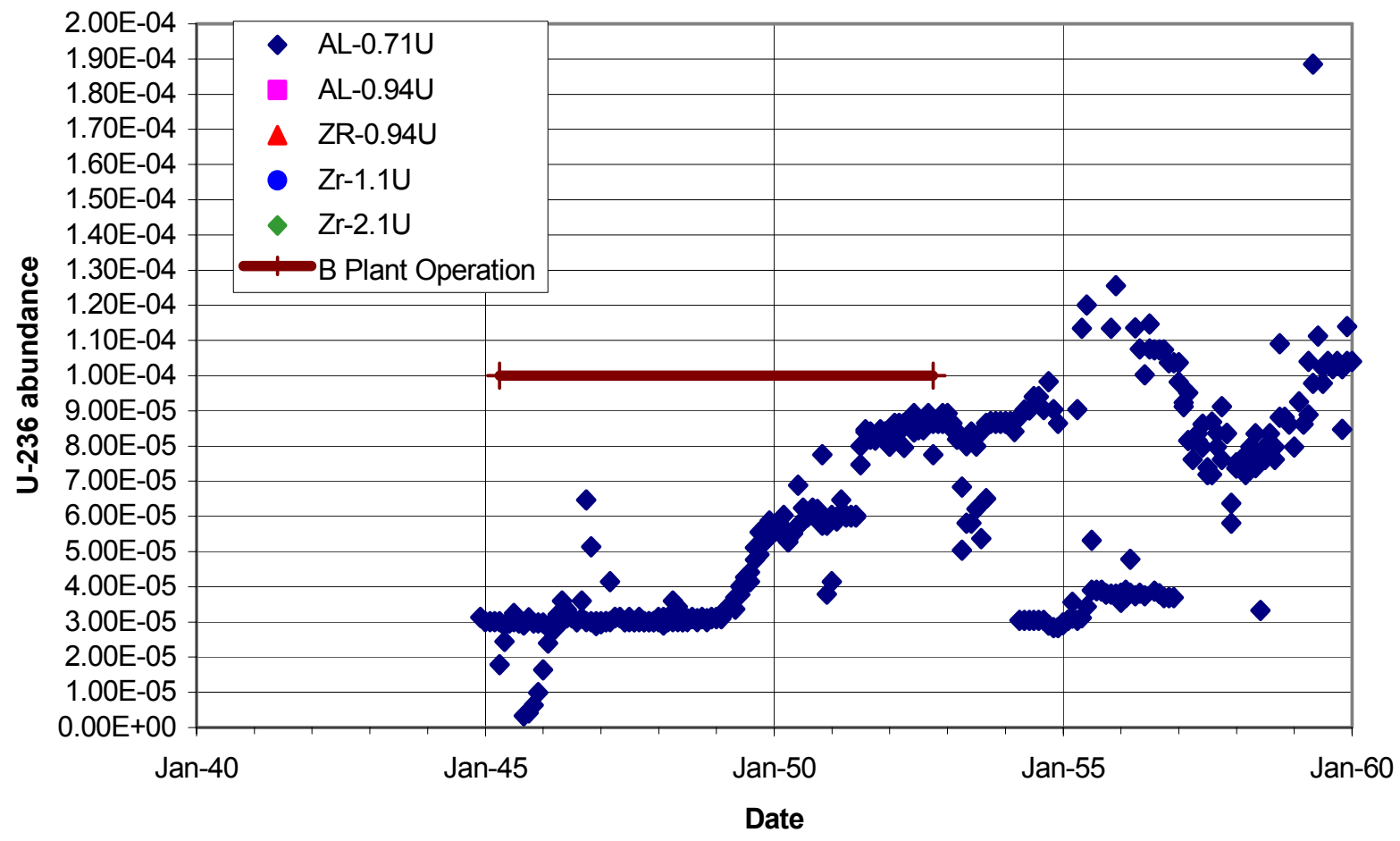

Figure 4.4. Detail of Uranium-236 Abundance for Hanford Reactor Fuel from the Early Production. See Table 1-1 for description of fuel types.

to that in the high concentration, high uranium-236 abundance samples from 200 East Area. The variability, however, precludes distinguishing a low-concentration, low uranium-236 contaminant from mixing between a higher uranium-236 abundance contaminant with background water.

Table 4.3 lists the operating period for facilities monitored by wells showing low uranium-236 abundance. The 216-B-62 crib, which is monitored by well 299-E28-18, received process condensate from B Plant after the facility was used for plutonium separation. Later use of B Plant was for recovery of radioisotopes from Hanford waste. It is unclear what uranium composition would have been present in this later operation. Wells 299-E28-2 and 299-E28-25 monitor the 216-B-5 injection well which received early waste from B Plant. The uranium isotopic composition is consistent with this source. As discussed below, the plutonium isotopic composition is also consistent with early production.

Table 4.3. Locations of Low Abundance Uranium-236 Samples in the 200 East Area

\begin{tabular}{||l|l|c|c|c||}
\hline Well Name & \multicolumn{1}{|c|}{ Near-by Facility } & $\begin{array}{c}\text { Facility Operation } \\
\text { Dates }\end{array}$ & $\begin{array}{c}\text { Total U } \\
\text { Concentration }\end{array}$ & $\begin{array}{c}\text { U-236 } \\
\text { Abundance }\end{array}$ \\
\hline \hline 299-E28-18 & 216-B-62 Crib & $1973-1991$ & $29.7 \mu \mathrm{g} / \mathrm{L}$ & $5.0 \mathrm{e}-5$ \\
\hline 299-E28-2 & 216-B-5 Injection Well & $1945-1947$ & $4.78 \mu \mathrm{g} / \mathrm{L}$ & $3.4 \mathrm{e}-5$ \\
\hline 299-E28-25 & 216-B-5 Injection Well & $1945-1947$ & $6.65 \mu \mathrm{g} / \mathrm{L}$ & $2.8 \mathrm{e}-5$ \\
\hline 299-E33-16 & 216-B-8 Crib & $1945-1954$ & $14.5 \mu \mathrm{g} / \mathrm{L}$ & $4.2 \mathrm{e}-5$ \\
\hline
\end{tabular}


There is some uncertainty regarding the operation dates for the $216-\mathrm{B}-8 \mathrm{crib}$, which is monitored by well 299-E33-16. Some sources indicate that it was only used until 1951. This crib received secondcycle waste supernatant from the B tank farm, beginning in 1948. This waste was released due to a lack of tank storage space. Uranium was not recovered from the waste in the bismuth phosphate process used in B Plant and, thus, higher concentrations were present than in the waste streams from subsequent processes. However, the majority of the uranium remained in the metal waste and first-cycle decontamination waste that were produced by earlier steps in the process than the second-cycle waste. In any case, it is likely that the majority of the uranium discharged to the 216-B-8 crib was from pre-1948 waste, which had been stored in the B tank farm until that time. This is consistent with the low uranium-236 abundance in the groundwater.

The high abundance uranium-236 in the 200 East Area is found in samples from a high-concentration uranium plume near the B-BX-BY tank farms. Uranium concentrations in this vicinity range to over $500 \mu \mathrm{g} / \mathrm{L}$. The uranium-236 abundance greater than 7e-5 is distinct from that of well 299-E33-16 which monitors the 216-B-8 crib located east of the tank farms. Thus, it appears that the uranium is from different sources. The higher uranium-236 abundance is consistent with AL-0.71U fuel batches from after approximately 1950. This fuel was processed in only approximately the last 3 years of B Plant operation. Similar uranium-236 abundance fuel was processed for longer at T Plant, REDOX Plant, and PUREX Plant so it is possible that waste from those facilities contributed.

Estimates of uranium isotopic composition of the most significant known leaks from tanks in the B-BX-BY tank farms are summarized in Jones et al. 2001. The uranium isotopic abundances for those leaks with an inventory calculated in that document are summarized in Table 4.4. The largest documented leak was 347,000 L from tank BX-102 in 1951. This leak was actually an overflow event rather

Table 4.4. Uranium Isotopic Estimates for Tank Leaks in the B-BX-BY Tank Farms

\begin{tabular}{||l|c|c|c|c|c|c||}
\hline \multicolumn{1}{|c|}{ Tank } & $\begin{array}{c}\text { Leak } \\
\text { Date }\end{array}$ & Volume-L & $\begin{array}{c}\text { U-234 } \\
\text { Abundance }\end{array}$ & $\begin{array}{c}\text { U-235 } \\
\text { Abundance }\end{array}$ & $\begin{array}{c}\text { U-236 } \\
\text { Abundance }\end{array}$ & $\begin{array}{c}\text { U-238 } \\
\text { Abundance }\end{array}$ \\
\hline \hline $241-\mathrm{B}-101$ & 1974 & 18,900 & $7.05 \mathrm{E}-05$ & $7.83 \mathrm{E}-03$ & $4.92 \mathrm{E}-04$ & $9.92 \mathrm{E}-01$ \\
\hline $241-\mathrm{B}-105$ & 1968 & 11,400 & $5.33 \mathrm{E}-05$ & $6.86 \mathrm{E}-03$ & $4.80 \mathrm{E}-05$ & $9.93 \mathrm{E}-01$ \\
\hline $241-\mathrm{B}-107$ & 1966 & 53,000 & $5.66 \mathrm{E}-05$ & $6.74 \mathrm{E}-03$ & $1.41 \mathrm{E}-04$ & $9.93 \mathrm{E}-01$ \\
\hline $241-\mathrm{B}-110$ & $1970 / 71$ & 95,000 & $5.76 \mathrm{E}-05$ & $6.83 \mathrm{E}-03$ & $1.66 \mathrm{E}-04$ & $9.93 \mathrm{E}-01$ \\
\hline $241-\mathrm{B}-201$ & 1966 & 4,540 & $5.35 \mathrm{E}-05$ & $6.83 \mathrm{E}-03$ & $4.49 \mathrm{E}-05$ & $9.93 \mathrm{E}-01$ \\
\hline $241-\mathrm{B}-203$ & 1966 & 1,140 & $5.35 \mathrm{E}-05$ & $6.86 \mathrm{E}-03$ & $4.48 \mathrm{E}-05$ & $9.93 \mathrm{E}-01$ \\
\hline $241-\mathrm{B}-204$ & 1966 & 1,510 & $5.33 \mathrm{E}-05$ & $6.84 \mathrm{E}-03$ & $4.46 \mathrm{E}-05$ & $9.93 \mathrm{E}-01$ \\
\hline $241-\mathrm{BX}-101$ & 1972 & 15,100 & $5.87 \mathrm{E}-05$ & $6.93 \mathrm{E}-03$ & $1.89 \mathrm{E}-04$ & $9.93 \mathrm{E}-01$ \\
\hline $241-\mathrm{BX}-102$ & 1951 & 347,000 & $5.30 \mathrm{E}-05$ & $6.74 \mathrm{E}-03$ & $5.22 \mathrm{E}-05$ & $9.93 \mathrm{E}-01$ \\
\hline $241-B X-111$ & 1965 & 15,100 & $5.71 \mathrm{E}-05$ & $6.77 \mathrm{E}-03$ & $1.56 \mathrm{E}-04$ & $9.93 \mathrm{E}-01$ \\
\hline
\end{tabular}


than a tank rupture. The uranium-236 abundance estimated for the BX-102 event is 5.22e-5, which is somewhat lower than the approximately $7 \mathrm{e}-5$ value seen in groundwater samples from the uranium plume. However, the uncertainties in the estimated values are not well known so this may still be a possible source. Samples from vadose zone contamination related to this leak could help resolve this question.

The low-concentration uranium samples in this data set illustrate another use for the uranium isotopic measurements. An issue regarding the source of low levels of tritium contamination in Richland North groundwater was raised during the course of this method development activity. The tritium levels, in the hundreds of $\mathrm{pCi} / \mathrm{L}$, were low but higher than currently seen in the Columbia River and higher than expected for groundwater in that area. The uranium isotopic composition was measured for several samples to help preclude any transport of contamination through the groundwater south from the 300 Area. The uranium results for the relevant samples from Tables 4.1 and 4.2 are summarized in Table 4.5. The samples are located in Figure 4.5. The drive-point sample was collected from a shallow piezometer, near the Columbia River Shoreline. All the samples are somewhat enriched in uranium-234 as expected for natural uranium in groundwater. Uranium-236 is not detected in the region between the 300 Area and the North Richland well field, indicating that there is no groundwater uranium transport through this area. Very low levels of uranium-236 were detected in well 1199-39-16D, located immediately adjacent to the North Richland well field. The city of Richland pumps water from the Columbia River into recharge basins next to the well field so the water is filtered by the sediment prior to use in the water supply. It is hypothesized that the low level of uranium-236 is from Columbia River water. It would be valuable to obtain river water samples and to resample this well to confirm the presence and the source of uranium-236.

Table 4.5. Uranium Isotopic Composition in Samples South of the 300 Area

\begin{tabular}{||l|c|c|c|c|c|c||}
\hline \multicolumn{1}{|c|}{ Well } & Date & $\begin{array}{c}\text { Total U } \\
\mu \mathrm{g} / \mathrm{L}\end{array}$ & $\begin{array}{c}\mathrm{U}-234 \\
\text { Abundance }\end{array}$ & $\begin{array}{c}\mathrm{U}-235 \\
\text { Abundance }\end{array}$ & $\begin{array}{c}\text { U-236 } \\
\text { Abundance }\end{array}$ & $\begin{array}{c}\text { U-238 } \\
\text { Abundance }\end{array}$ \\
\hline \hline Natural Abundance & & & $\mathbf{5 . 5 0 E - 0 5}$ & $\mathbf{7 . 2 0 E - 0 3}$ & $\mathbf{0 . 0 0 E + 0 0}$ & $\mathbf{9 . 9 3 E - 0 1}$ \\
\hline $\begin{array}{l}\text { Drive Point by } \\
\text { Well 3099-47-18B }\end{array}$ & $09 / 30 / 99$ & 1.945 & $6.27 \mathrm{E}-05$ & $7.37 \mathrm{E}-03$ & N.D. & $9.93 \mathrm{E}-01$ \\
\hline $1199-39-16 \mathrm{D}$ & $09 / 26 / 99$ & 0.307 & $7.38 \mathrm{E}-05$ & $6.97 \mathrm{E}-03$ & $1.24 \mathrm{E}-05$ & $9.93 \mathrm{E}-01$ \\
\hline 1199-39-16D & $09 / 26 / 99$ & 0.317 & $7.59 \mathrm{E}-05$ & $6.98 \mathrm{E}-03$ & $1.41 \mathrm{E}-05$ & $9.93 \mathrm{E}-01$ \\
\hline 699-S29-E16A & $09 / 22 / 99$ & 4.029 & $6.00 \mathrm{E}-05$ & $7.02 \mathrm{E}-03$ & N.D. & $9.93 \mathrm{E}-01$ \\
\hline 699-S37-E14 & $09 / 20 / 99$ & 1.934 & $6.33 \mathrm{E}-05$ & $7.06 \mathrm{E}-03$ & N.D. & $9.93 \mathrm{E}-01$ \\
\hline 699-S43-E12 & $09 / 24 / 99$ & 5.077 & $6.25 \mathrm{E}-05$ & $7.24 \mathrm{E}-03$ & N.D. & $9.93 \mathrm{E}-01$ \\
\hline N.D. = Not detected. & & & & \\
\hline
\end{tabular}




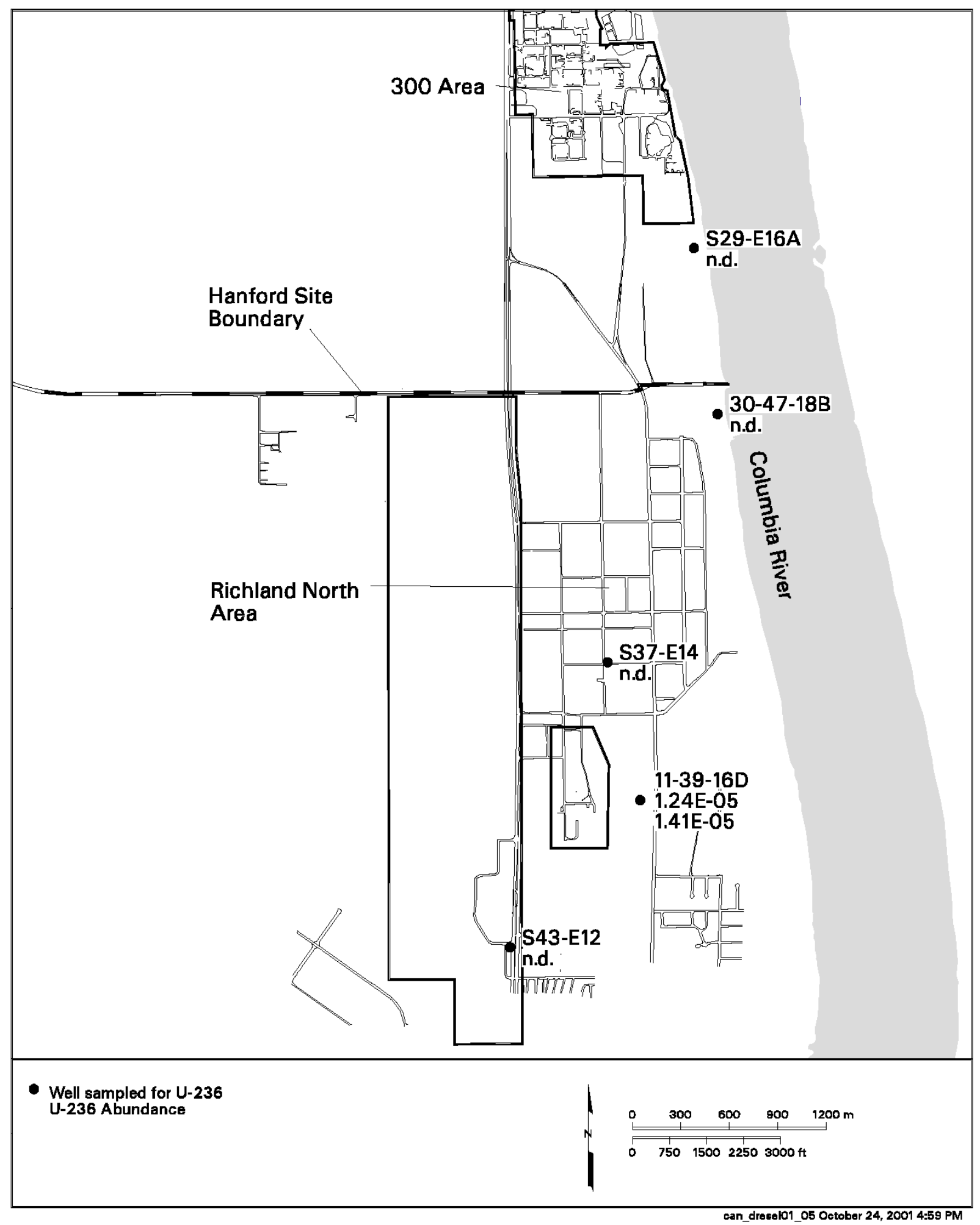

Figure 4.5. Uranium-236 Abundance for Groundwater Samples from Richland North 


\subsection{Plutonium}

Samples were collected for plutonium isotopic measurements in conjunction with a study of colloidal transport at the 216-B-5 injection well. This report will summarize the results from bulk groundwater samples collected. Samples were collected from two wells and analyzed for plutonium isotopics without filtration. Samples were analyzed by both alpha spectroscopy and ICP-MS.

The 216-B-5 injection well was used between 1945 and 1947 for the disposal of alkaline, low-salt, intermediate level radioactive waste from the bismuth phosphate process at B Plant. The well was perforated across the water table. Approximately 3.1e7 liters of waste containing approximately $4.3 \mathrm{~kg}$ of plutonium were discharged to the system. According to Smith (1980), approximately half the inventory of plutonium remained in a settling tank prior to discharge to ground.

Samples were collected using low flow sampling from two wells. Well 299-E28-25 is located approximately 3 meters northwest of the injection well. Well 299-E28-2 is located approximately 100 meters northwest of the injection well. Plutonium-239+240 in well 299-E28-25 is easily detectable by conventional alpha spectroscopy but that method does not distinguish between plutonium-239 and plutonium-240. Prior to 1999, when these samples were collected, plutonium concentrations in well 299-E28-2 had declined below detection levels for alpha spectroscopy. The 1999 results for alpha spectroscopy and ICP-MS are summarized in Table 4.6.

Plutonium-239+240 was not detected in conventional alpha spectroscopy measurement of samples from well 299-E28-2. This is consistent with previous results. Plutonium-239 was detected in ICP-MS samples from this well. The plutonium-240 measurement is high for the mid sample from well 299E28-2 compared to the plutonium-239 and is considered suspect. The plutonium-239/240 ratio for this sample is inconsistent with process knowledge. It is likely that a single-channel transient spike in the instrument produced the elevated plutonium-240. No plutonium-240 was detected in other ICP-MS measurements from this well. The plutonium results from well 299-E28-25 are above detection limits for both methods and the values are in reasonable agreement with a maximum relative percent difference of $33 \%$.

Table 4.6. Results of Plutonium Analysis by ICP-MS with Preconcentration/Separation

\begin{tabular}{||l|l|l|c|c|c|c|c||}
\hline Well Name & $\begin{array}{c}\text { Sample } \\
\text { Date/Time }\end{array}$ & $\begin{array}{c}\text { Sample } \\
\text { Number }\end{array}$ & $\begin{array}{c}\text { Pu-239 } \\
\text { pCi/1 }\end{array}$ & $\begin{array}{c}\text { Pu-240 } \\
\text { pCi/1 }\end{array}$ & $\begin{array}{c}\text { Pu-239/240 } \\
\text { Total pCi/L }\end{array}$ & $\begin{array}{c}\text { Pu-240/239+240 by } \\
\text { Atom Ratio }\end{array}$ & $\begin{array}{c}\text { Alpha Spectroscopy } \\
\text { pCi/L }\end{array}$ \\
\hline \hline 299-E28-2 & $8 / 8 / 999: 55$ & BOW419 & 0.02 & N.D. & 0.02 & -- & -0.0123 \\
\hline $299-E 28-2$ & $8 / 8 / 9918: 58$ & BOW421 & 0.02 & 0.04 & 0.06 & 0.500 & -- \\
\hline 299-E28-2 & $8 / 9 / 994: 50$ & BOW424 & 0.02 & N.D. & 0.02 & -- & -0.00364 \\
\hline 299-E28-25 & $8 / 10 / 9912: 26$ & BOW444 & 2.23 & 0.12 & 2.35 & 0.015 & 2.63 \\
\hline 299-E28-25 & $8 / 10 / 9921: 15$ & BOW449 & 2.03 & 0.09 & 2.12 & 0.013 & -- \\
\hline 299-E28-25 & $8 / 11 / 996: 03$ & BOW446 & 1.46 & 0.09 & 1.56 & 0.017 & 1.05 \\
\hline N.D. = Not detected.
\end{tabular}


The samples from well 299-E28-25 show an extremely low content of plutonium-240 with an average plutonium-240:plutonium-239 atom ratio of 0.015. The average plutonium-240:plutonium-239 atom ratio calculated from the ORIGEN2 simulations of B Plant fuel from 1944 through 1947 is 0.014, showing excellent agreement. By comparison, atmospheric fallout plutonium exhibits ratios of 0.180 for the northern hemisphere between 30 and 70 degrees N. Nevada Test Site local fallout has a ratio of 0.0321 (Kelley et al. 1999). In contrast, the local or tropospheric fall out in sediments and water near the Pacific Proving Grounds has a ratio greater than global fall-out with values $>0.20$ and in some samples greater than 0.30 (Buessler 1997).

This limited study shows that the ICP-MS measurements can significantly improve detection limits for plutonium over the conventional alpha spectroscopy method. The ICP-MS measurements provide information on plutonium-240:plutonium-239 atom ratios, which are unavailable from alpha spectroscopy. The atom ratio is useful in distinguishing plutonium sources. The plutonium-240:plutonium-239 ratio can be determined using thermal ionization mass spectrometry but the costs are higher and sample throughput is lower.

\subsection{Ruthenium}

Ruthenium-106 was a major contributor to total beta activity in groundwater during Hanford production. However, the short ruthenium-106 half life of 1.02 years means that the activity has decayed to insignificant levels. The extensive ruthenium-106 plumes detected during the operational period demonstrate that fission ruthenium is highly mobile in the Hanford unconfined aquifer. Thus, we expected to see fission-derived stable ruthenium in groundwater samples.

Isobaric interference from molybdenum and technetium preclude quantification of ruthenium-96, -98, -99 , and -100 . Ruthenium-101, -102 , and -104 are fission products with distinctly different fission yields than the natural abundances (Table 4.7). These isotopes can be measured by ICP-MS and used to identify fission sources. The ratio of each isotope to the total for all three can be compared to the natural ratio of the three isotopes and the fission ratio.

In 2001, ruthenium and molybdenum isotopic composition was measured on a series of samples originally collected for uranium isotopic analysis. Most of these samples were collected from the

Table 4.7. Isotopic Ratios of Ruthenium from Natural and Fission Abundance

\begin{tabular}{||l|c|c|c||}
\hline & $\mathrm{Ru}-101$ & $\mathrm{Ru}-102$ & $\mathrm{Ru}-104$ \\
\hline \hline Natural Abundance (atom \%) & 17 & 31.6 & 18.7 \\
\hline Natural Ratio & $\mathbf{0 . 2 5 2 6}$ & $\mathbf{0 . 4 6 9 5}$ & $\mathbf{0 . 2 7 7 9}$ \\
\hline & & & \\
\hline Fission Yield from U-235 (atom \%) & 5.2 & 4.3 & 1.88 \\
\hline Fission Ratio from U-235 & $\mathbf{0 . 4 5 6 9}$ & $\mathbf{0 . 3 7 7 9}$ & $\mathbf{0 . 1 6 5 3}$ \\
\hline
\end{tabular}


northwestern 200 East Area, near the BY cribs and Waste Management Area B-BX-BY. One sample was from the 216-B-62 crib (west of B Plant), one sample near T Plant in the 200 West Area, and one sample near the southern boundary of the site in Richland North. The ruthenium isotopic ratios for the samples are listed in Table 4.8. Ruthenium concentrations are listed in Table 4.9.

Of the eight samples with detectable ruthenium, the seven samples from the 200 East Area, near the BY cribs, show isotopic abundance close to that for fission-derived ruthenium and distinct from natural isotopic abundance. The sample from the 200 West Area contains ruthenium with an abundance ratio close to natural. The source of this natural-abundance ruthenium is unknown.

Table 4.8. Isotopic Ratios of Ruthenium in Hanford Groundwater Samples

\begin{tabular}{||l|c|c|c|c|c||}
\hline \multicolumn{1}{|c|}{ Well Name } & SAMP ID & Ru-101 Ratio & Ru-102 Ratio & Ru-104 Ratio & Notes \\
\hline \hline 299-E28-18 & B11VB5 & 0.082 & 0.212 & 0.705 & non detect \\
\hline 699-S31-E10B & B11VB8 & -0.045 & 0.126 & 0.919 & non detect \\
\hline 299-E33-9 & B11V99 & 0.448 & 0.359 & 0.194 & \\
\hline 299-E33-16 & B11VB0 & 0.423 & 0.348 & 0.229 & \\
\hline 299-E33-26 & B11VB1 & 0.450 & 0.355 & 0.195 & \\
\hline 299-E33-18 & B11VB2 & 0.435 & 0.348 & 0.217 & \\
\hline 299-E33-38 & B11VB3 & 0.448 & 0.357 & 0.195 & \\
\hline 299-E33-38 & B11VB4 & 0.447 & 0.357 & 0.196 & \\
\hline 299-E33-44 & B11VB6 & 0.441 & 0.355 & 0.203 & \\
\hline 299-W11-14 & B11VB7 & 0.282 & 0.444 & 0.274 & Not fission abundance \\
\hline
\end{tabular}

Table 4.9. Concentrations of Ruthenium Isotopes and Total for the Three Quantified Isotopes in Hanford Groundwater

\begin{tabular}{|c|c|c|c|c|c|c|}
\hline Well Name & SAMP ID & $\begin{array}{c}\mathrm{Ru}-101 \\
\mu \mathrm{g} / \mathrm{L}\end{array}$ & $\begin{array}{c}\mathrm{Ru}-102 \\
\mu \mathrm{g} / \mathrm{L}\end{array}$ & $\begin{array}{c}\text { Ru-104 } \\
\mu \mathrm{g} / \mathrm{L}\end{array}$ & $\begin{array}{l}\text { Total } \\
\mu \mathrm{g} / \mathrm{L}\end{array}$ & Notes \\
\hline 299-E28-18 & B11VB5 & 0.0000 & 0.0000 & 0.0001 & 0.0002 & non detect \\
\hline 699-S31-E10B & B11VB8 & 0.0000 & 0.0000 & 0.0002 & 0.0003 & non detect \\
\hline 299-E33-9 & B11V99 & 0.0398 & 0.0322 & 0.0177 & 0.0898 & \\
\hline 299-E33-16 & B11VB0 & 0.0029 & 0.0024 & 0.0016 & 0.0069 & \\
\hline 299-E33-26 & B11VB1 & 0.0565 & 0.0450 & 0.0252 & 0.1267 & \\
\hline 299-E33-18 & B11VB2 & 0.0027 & 0.0022 & 0.0014 & 0.0062 & \\
\hline 299-E33-38 & B11VB3 & 0.0578 & 0.0464 & 0.0259 & 0.1301 & \\
\hline 299-E33-38 & B11VB4 & 0.0635 & 0.0512 & 0.0286 & 0.1433 & \\
\hline 299-E33-44 & B11VB6 & 0.0076 & 0.0062 & 0.0036 & 0.0174 & \\
\hline 299-W11-14 & B11VB7 & 0.0047 & 0.0075 & 0.0047 & 0.0169 & Not fission abundance \\
\hline
\end{tabular}


Closer examination of the ruthenium isotopic ratios shows that the ratio is systematically lower than the uranium-235 fission ratio for ruthenium-101 and ruthenium-102 but higher than uranium-235 fission yield for ruthenium-104 (Figures 4.6, 4.7, and 4.8). This may be explained by the contribution from plutonium-239 fission in the reactors. The figures show the expected ratios for uranium-235 and plutonium-239 fission, as well as the ratios calculated from the average of all Hanford fuel loads as calculated using the ORIGEN-2 and DKPRO codes. When the ruthenium isotopic ratios are plotted on a figure of ruthenium-101:ruthenium-104 versus ruthenium-102:ruthenium:104, the samples from the 200 East Area fall close to the line between uranium-235 fission and plutonium-239 fission (Figure 4.9). The spread along the line indicates varying contribution from plutonium to the fission products. The sample from the 200 West Area falls near the natural abundance point. All samples show a bias toward high ruthenium-101 and low ruthenium-102 or low ruthenium-104. This suggests a small systematic error in the measurements.

Isotopes of several other elements also were measured during the ruthenium and molybdenum analysis. These include technetium-99, rhodium-103, and palladium-105, which are all fission products. These isotopes were not quantified with standards, but the relative counts versus ruthenium provide a good estimate of the atomic ratios between the elements. These ratios then can be compared to the expected fission yield. The ratio of blank-corrected counts for technetium-99, rhodium-103, and

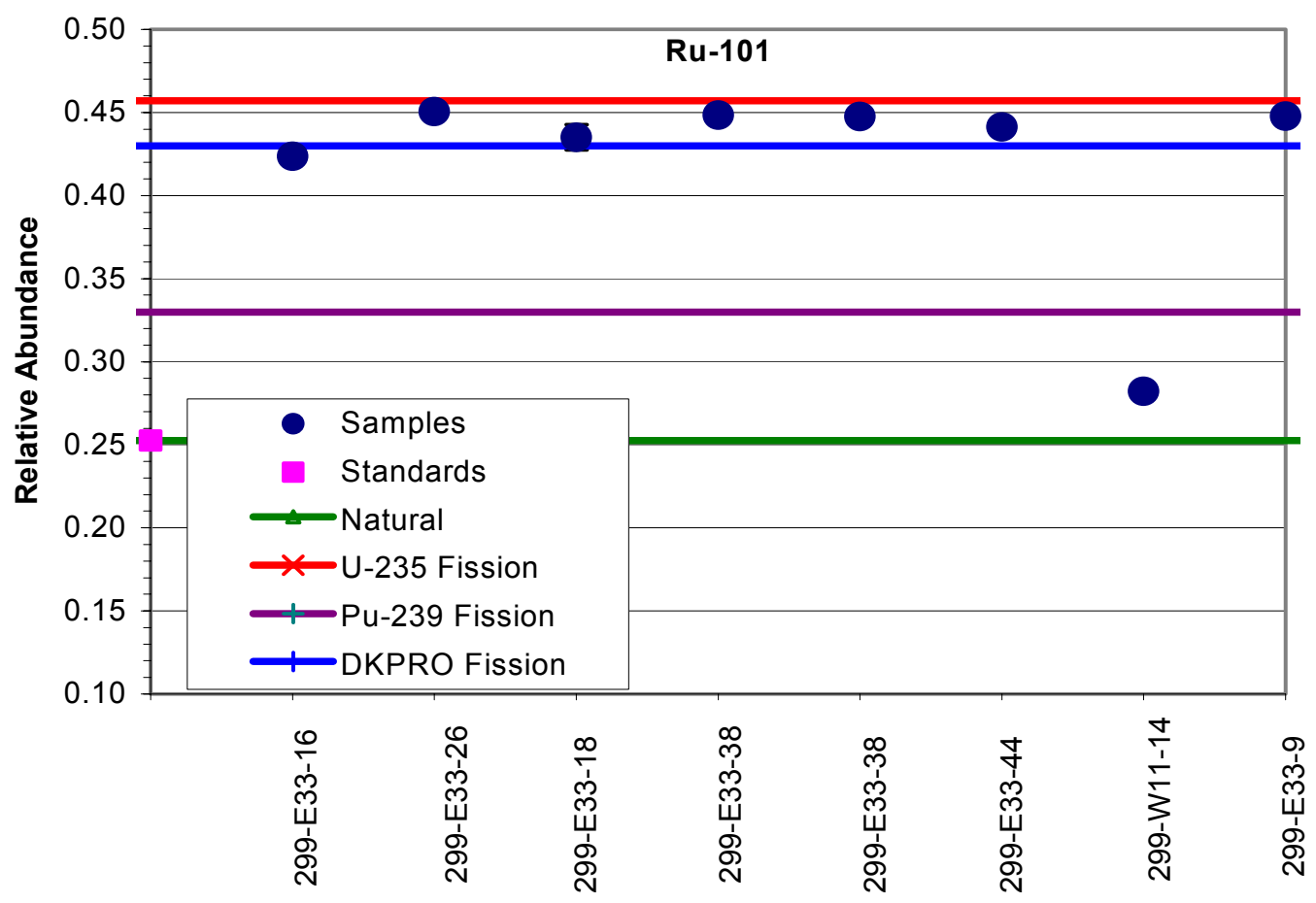

Figure 4.6. Relative Abundance of Ruthenium-101 to the Sum of Ruthenium-101, -102, -104 in Hanford Groundwater Samples Compared to Natural and Fission Ratios 


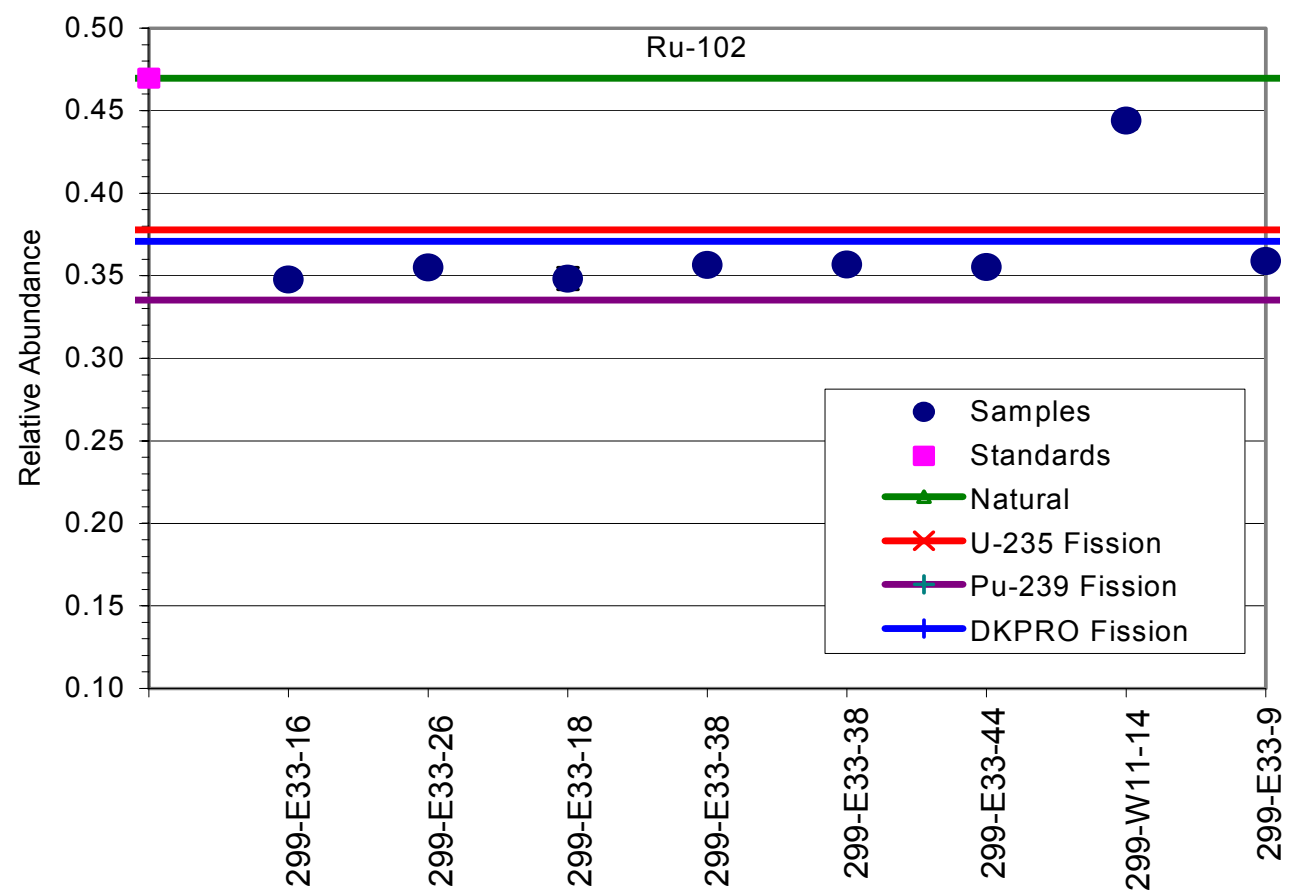

Figure 4.7. Relative Abundance of Ruthenium-102 to the Sum of Ruthenium-101, -102, -104 in Hanford Groundwater Samples Compared to Natural and Fission Ratios

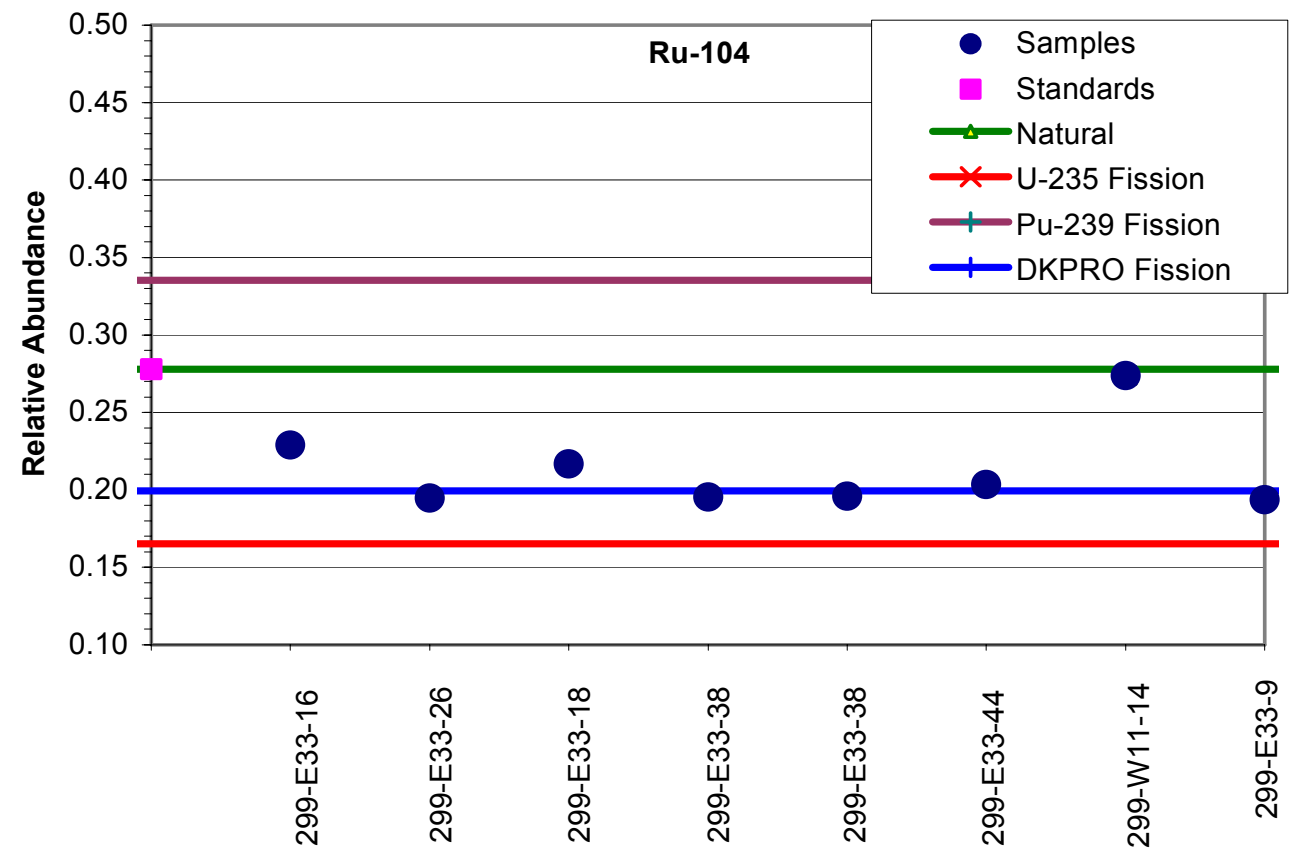

Figure 4.8. Relative Abundance of Ruthenium-104 to the Sum of Ruthenium-101, -102, -104 in Hanford Groundwater Samples Compared to Natural and Fission Ratios 


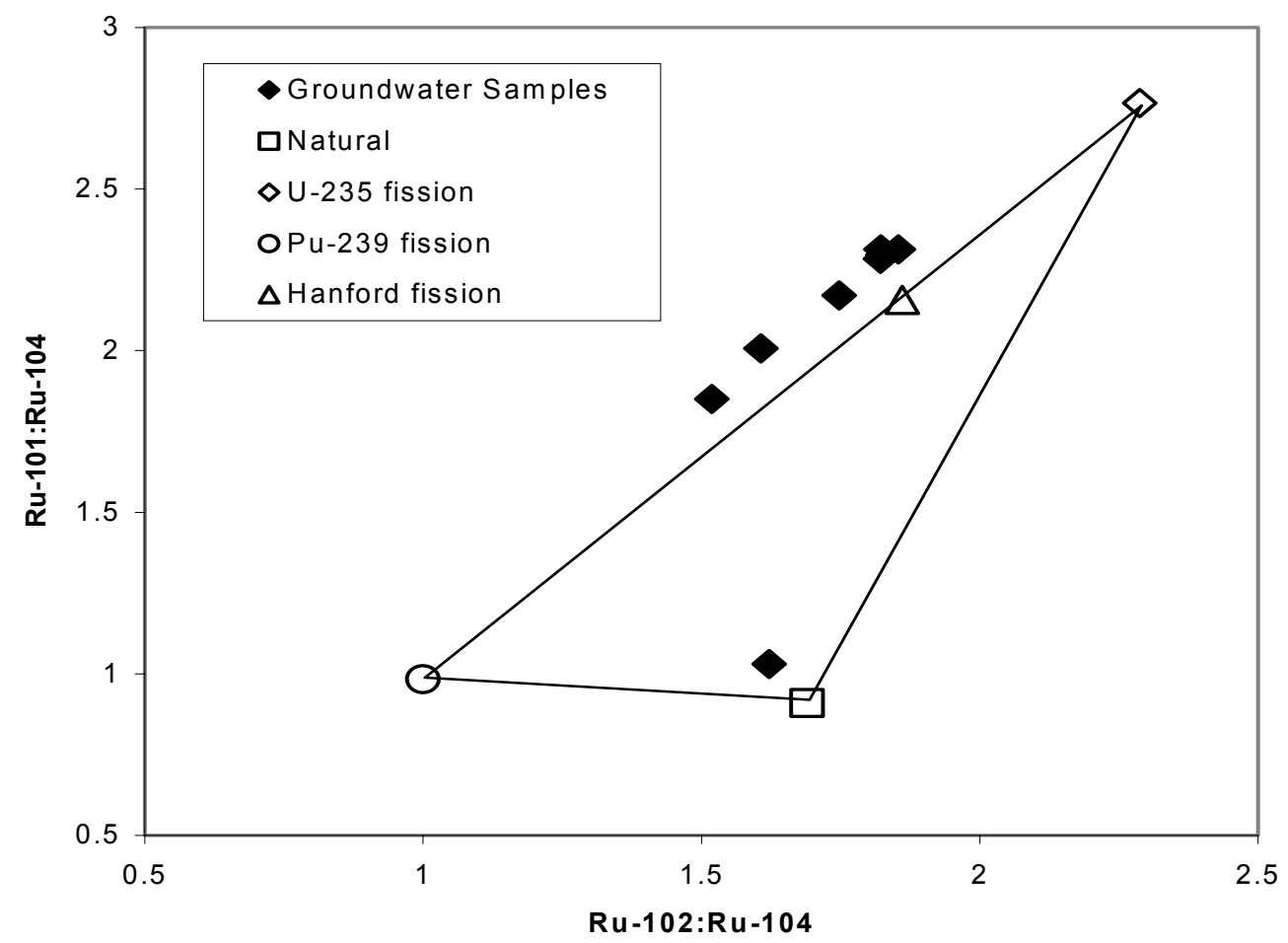

Figure 4.9. Ruthenium-101:Ruthenium-104 Ratio versus Ruthenium-102:Ruthenium-104 Ratio for Hanford Groundwater Samples Compared to Natural and Fission Ratios

palladium-105 versus ruthenium-101 are shown in Table 4.10 for samples from the 200 East Area near the BY cribs and the B-BX-BY tank farms. The results show that ruthenium is generally low compared to fission technetium-99 and rhodium-103. The data show two distinct groupings of technetium-99: ruthenium-101. Samples located north of the B tank farm, near the 216-B-8 crib, have higher ratios than samples further west (Figure 4.10). The same pattern hold true for the rhodium-103:ruthenium-101 ratios. This should be confirmed by further study but the results suggest that there are two sources of technetium-99 in this area.

It is also possible that differential transport in the groundwater affects the technetium:ruthenium ratios due to differing geochemical properties between technetium and ruthenium. However, the samples with the high technetium-99:ruthenium-101 ratio are the samples with the lowest ruthenium-101:ruthenium104 ratio, i.e. the greatest contribution from plutionium-239 fission. The ruthenium isotopes would not be fractionated by geochemical processes so this indicates that there are multiple sources of contamination in this area.

\subsection{Molybdenum}

Molybdenum isotopes were measured on the same suite of samples as ruthenium. The molybdenum isotopic composition of all samples was very close to natural abundance (Table 4.11). The interfering zirconium ion concentrations were subtracted for the molybdenum-92, -94, and -96 measurements and, 
Table 4.10. Technetium-99, Rhodium-103, and Palladium-105 Ratios to Ruthenium-101 in Groundwater Samples from the 200 East Area, near the BY Cribs and the B-BX-BY Tank Farms

\begin{tabular}{||l|l|c|c|c||}
\hline Well Name & SAMP ID & Tc-99:Ru-101 & Rh-103:Ru-101 & Pd-105:Ru-101 \\
\hline \hline & Fission Ratio & $\mathbf{1 . 1 7}$ & $\mathbf{0 . 5 8}$ & $\mathbf{0 . 1 8}$ \\
\hline 299-E33-9 & B11V99 & 9.97 & 4.41 & 0.03 \\
\hline 299-E33-16 & B11VB0 & 56.41 & 15.63 & 0.64 \\
\hline 299-E33-26 & B11VB1 & 12.58 & 3.91 & 0.29 \\
\hline 299-E33-18 & B11VB2 & 83.20 & 31.65 & 0.09 \\
\hline 299-E33-38 & B11VB3 & 14.85 & 4.01 & 0.28 \\
\hline 299-E33-38 & B11VB4 & 14.79 & 4.03 & 0.28 \\
\hline 299-E33-44 & B11VB6 & 40.20 & 13.30 & 0.17 \\
\hline
\end{tabular}

thus, those isotopes are subject to somewhat greater uncertainties. The other isotopes are free from this interference and the ratio between molybdenum-95, -97, -98, and -100 only was calculated and compared to the natural ratio for these isotopes. The isotopic ratios for the zirconium interference-free isotopes are shown in Table 4.12. Molybdenum results were not corrected for ruthenium because even for the single sample with apparent natural ruthenium, the correction is minor. No fission component can be seen in these samples. Figure 4.11 shows the results for the relative ratio of molybdenum- 98 based on molybdenum-95, $-97,-98$, and -100 . Molydenum- 98 shows the greatest difference in ratio between natural and fission.

These groundwater results for molybdenum isotopic composition contrast with the molybdenum results from vadose zone core collected in the SX tank farm. In the vadose zone cores, fission-produced molybdenum dominated in water extracts from the contaminated zones (Figure 4.12). Acid extracts leached significant amounts of the mineral matrix, contributing natural abundance material. Fission ruthenium was not detected in the core samples. The difference is likely because the SX tank farm waste was from the REDOX process and the 200 East Area waste was dominantly from the bismuth phosphate process. Although the presence of natural molybdenum in the groundwater samples could mask a fission contribution, the fission molybdenum would have produced a measurable shift in the ratios if molybdenum were present in an amount proportional to the ruthenium fission component. Thus, it appears that molybdenum was separated from the ruthenium and technetium during the bismuth phosphate process or during uranium recovery operations.

\subsection{Chlorine-36}

This section of the report summarizes chlorine-36 measurements on groundwater samples collected from the Hanford Site in 1995. These data have not yet been included in a PNNL report but have been presented orally (Dresel 1997). Little is known about chlorine-36 concentrations in Hanford waste but substantial amounts can be expected from process knowledge. Chlorine-36 is believed to be a good tracer for contaminants in groundwater because of the high mobility of chloride. The 1995 sampling confirms 


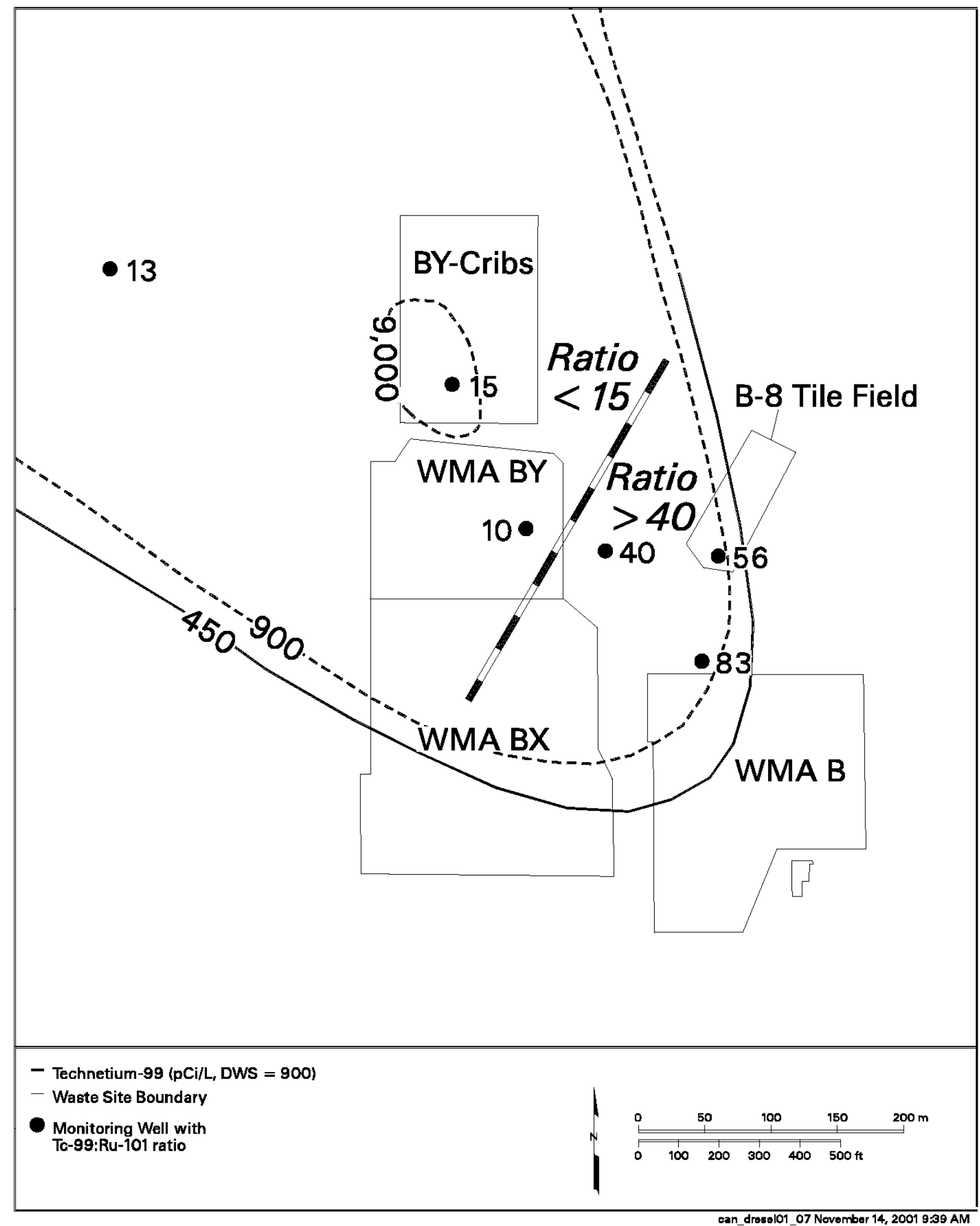

Figure 4.10. Technetium-99:Ruthenium-101 Ratios in the Vicinity of the BY Cribs and B-BX-BY Tank Farms 
Table 4.11. Molybdenum Isotopic Abundance in Hanford Groundwater Samples

\begin{tabular}{||l|l|c|c|c|c|c|c|c||}
\hline Well Name & SAMP ID & Mo-92 & Mo-94 & Mo-95 & Mo-96 & Mo-97 & Mo-98 & Mo-100 \\
\hline \hline & Natural & $\mathbf{0 . 1 4 8}$ & $\mathbf{0 . 0 9 3}$ & $\mathbf{0 . 1 5 9}$ & $\mathbf{0 . 1 6 7}$ & $\mathbf{0 . 0 9 6}$ & $\mathbf{0 . 2 4 1}$ & $\mathbf{0 . 0 9 6}$ \\
\hline & Fission & $\mathbf{0 . 1 4 5}$ & $\mathbf{0 . 1 3 4}$ & $\mathbf{0 . 1 3 8}$ & $\mathbf{0 . 1 4 5}$ & $\mathbf{0 . 1 5 0}$ & $\mathbf{0 . 1 4 9}$ & $\mathbf{0 . 1 3 9}$ \\
\hline 299-E28-18 & B11VB5 & 0.148 & 0.092 & 0.159 & 0.167 & 0.095 & 0.241 & 0.096 \\
\hline 699-S31-E10B & B11VB8 & 0.148 & 0.093 & 0.159 & 0.167 & 0.095 & 0.242 & 0.097 \\
\hline 299-E33-9 & B11V99 & 0.148 & 0.092 & 0.159 & 0.166 & 0.095 & 0.242 & 0.097 \\
\hline 299-E33-16 & B11VB0 & 0.148 & 0.092 & 0.159 & 0.166 & 0.095 & 0.242 & 0.096 \\
\hline 299-E33-26 & B11VB1 & 0.147 & 0.092 & 0.159 & 0.166 & 0.096 & 0.243 & 0.097 \\
\hline 299-E33-18 & B11VB2 & 0.148 & 0.092 & 0.160 & 0.166 & 0.096 & 0.242 & 0.096 \\
\hline 299-E33-38 & B11VB3 & 0.147 & 0.092 & 0.160 & 0.166 & 0.096 & 0.242 & 0.097 \\
\hline 299-E33-38 & B11VB4 & 0.147 & 0.092 & 0.160 & 0.166 & 0.096 & 0.243 & 0.097 \\
\hline 299-E33-44 & B11VB6 & 0.149 & 0.092 & 0.159 & 0.167 & 0.095 & 0.241 & 0.097 \\
\hline 299-W11-14 & B11VB7 & 0.148 & 0.092 & 0.159 & 0.167 & 0.095 & 0.241 & 0.097 \\
\hline
\end{tabular}

Table 4.12. Relative Isotopic Ratio of Molybdenum-95, $-97,-98$, and -100 in Hanford Groundwater Samples

\begin{tabular}{||l|l|c|c|c|c||}
\hline \multicolumn{1}{|c|}{ Well Name } & SAMP ID & Mo-95 & Mo-97 & Mo-98 & Mo-100 \\
\hline \hline & Natural & $\mathbf{0 . 2 6 9}$ & $\mathbf{0 . 1 6 1}$ & $\mathbf{0 . 4 0 7}$ & $\mathbf{0 . 1 6 3}$ \\
\hline & Fission & $\mathbf{0 . 2 6 4}$ & $\mathbf{0 . 2 4 4}$ & $\mathbf{0 . 2 3 6}$ & $\mathbf{0 . 2 5 6}$ \\
\hline 299-E28-18 & B11VB5 & 0.269 & 0.161 & 0.407 & 0.163 \\
\hline 699-S31-E10B & B11VB8 & 0.269 & 0.161 & 0.408 & 0.163 \\
\hline 299-E33-9 & B11V99 & 0.269 & 0.161 & 0.407 & 0.163 \\
\hline 299-E33-16 & B11VB0 & 0.268 & 0.161 & 0.408 & 0.163 \\
\hline 299-E33-26 & B11VB1 & 0.268 & 0.162 & 0.407 & 0.163 \\
\hline 299-E33-18 & B11VB2 & 0.269 & 0.161 & 0.408 & 0.163 \\
\hline 299-E33-38 & B11VB3 & 0.268 & 0.161 & 0.407 & 0.163 \\
\hline 299-E33-38 & B11VB4 & 0.268 & 0.161 & 0.407 & 0.164 \\
\hline 299-E33-44 & B11VB6 & 0.269 & 0.161 & 0.407 & 0.163 \\
\hline 299-W11-14 & B11VB7 & 0.269 & 0.160 & 0.407 & 0.164 \\
\hline \hline
\end{tabular}

the presence of large concentrations of chlorine-36 in the groundwater (Table 4.13). The maximum chlorine-36 concentration detected, $94.3 \mathrm{pCi} / \mathrm{L}$, corresponds to a potential ingestion dose of less than $0.2 \mathrm{mrem} / \mathrm{yr}$. The variability in chlorine-36 concentrations and in chlorine-36:chloride ratios suggests that further investigation as a signature would be productive. 


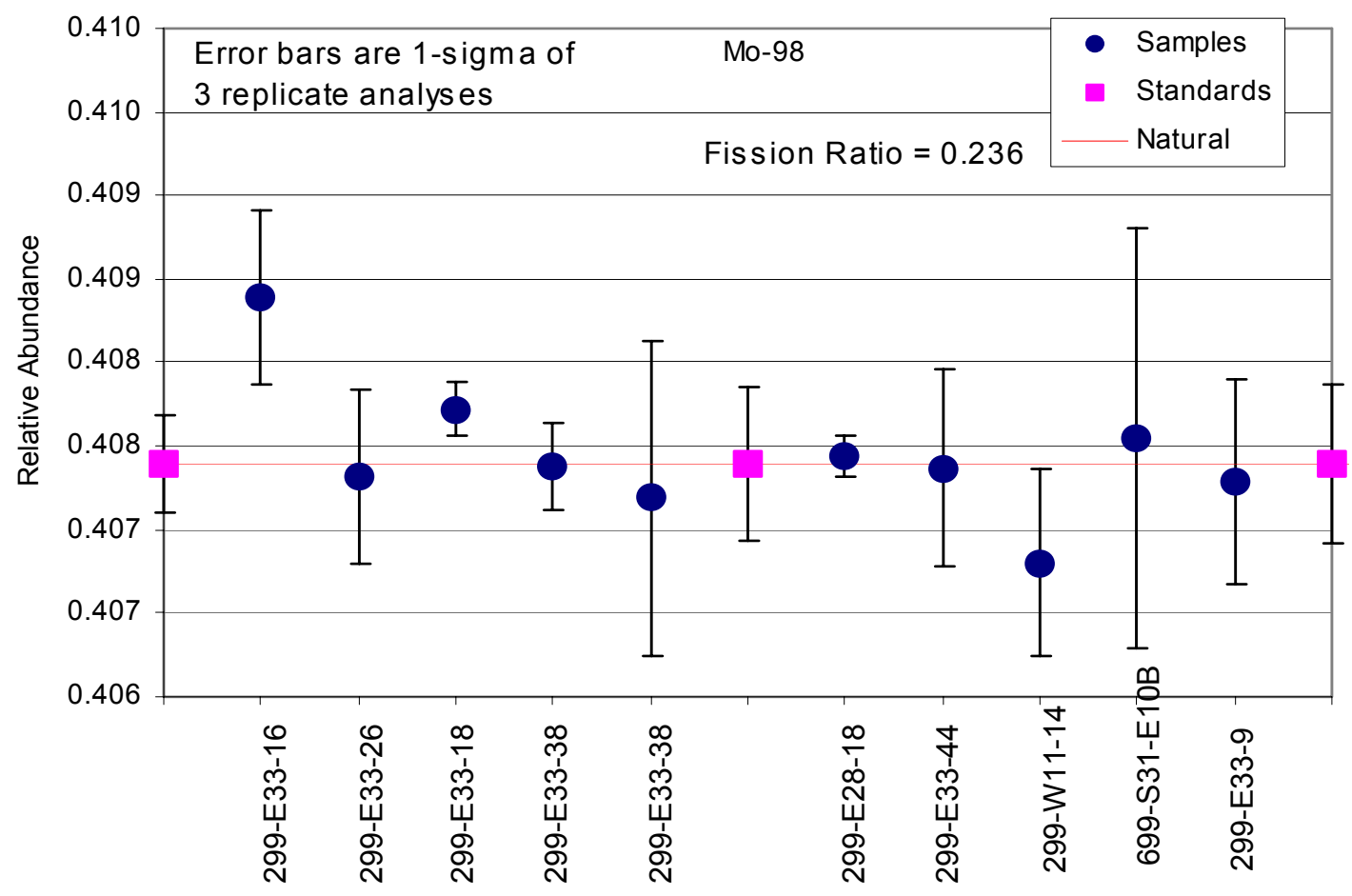

Figure 4.11. Abundance Ratio of Molybdenum-98 to Total Molybdenum-95, -97, -98, and -100 for Hanford Groundwater Samples

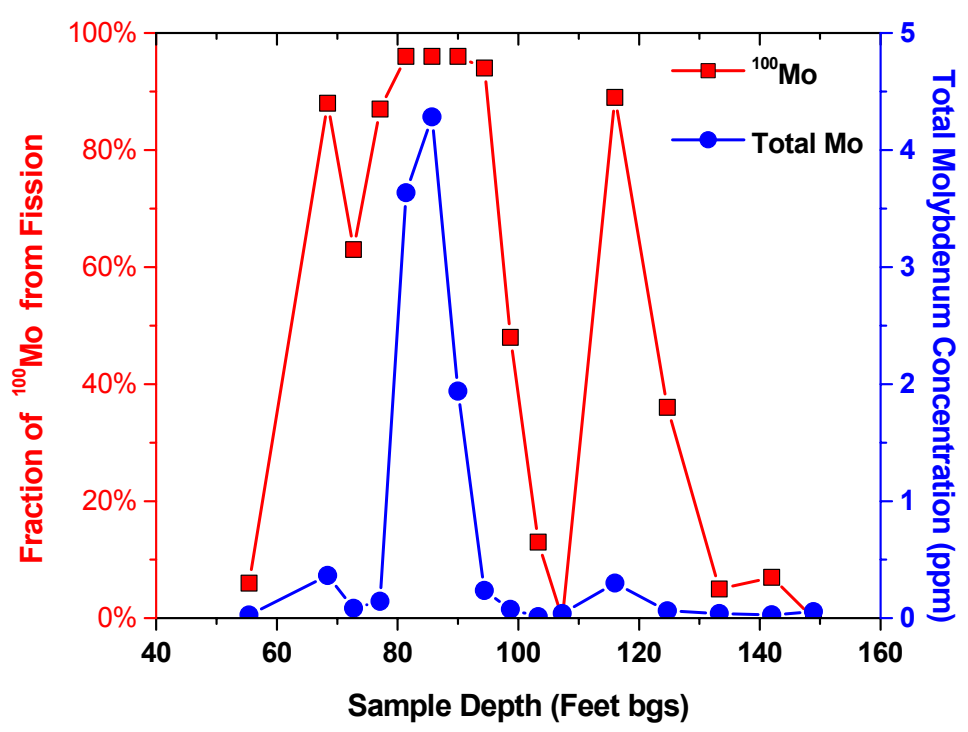

Figure 4.12. Comparison of Total Molybdenum (right axis) in Water Extracts from SX-108 Slant Borehole with Fission Derived ${ }^{100}$ Mo (left axis) 
Table 4.13. Chlorine-36 Measurements of Hanford Groundwater

\begin{tabular}{|c|c|c|c|c|c|c|c|c|}
\hline Well & $\begin{array}{l}\text { Sample } \\
\text { Number }\end{array}$ & $\begin{array}{c}\text { Chloride } \\
\mu \mathrm{g} / \mathrm{L}\end{array}$ & $\begin{array}{c}\mathrm{Cl}-36 / \mathrm{Cl} \\
10 \mathrm{e}-15 \\
\text { atom/atom }\end{array}$ & $\begin{array}{c}\text { Uncertainty } \\
+/-\end{array}$ & $\begin{array}{c}\mathrm{Cl}-36 \\
10 \mathrm{e} 10 \\
\text { atoms/L }\end{array}$ & Uncertainty & $\begin{array}{c}\mathrm{Cl}-36 \\
\mathrm{~g} / \mathrm{L}\end{array}$ & $\begin{array}{l}\mathrm{Cl}-36 \\
\mathrm{pCi} / \mathrm{L}\end{array}$ \\
\hline 199-F8-1 & В0СТ43 & 13,024 & $216,000,000$ & $9,300,000$ & 4778 & 206 & 2.86E-09 & 94.3 \\
\hline 199-K-30 & B0CT44 & 4,534 & $25,500,000$ & $1,000,000$ & 196.1 & 7.4 & $1.17 \mathrm{E}-10$ & 3.87 \\
\hline $199-\mathrm{N}-54$ & B0CT45 & 17,869 & 115,800 & 1,500 & 3.514 & 0.048 & $2.10 \mathrm{E}-12$ & 0.0694 \\
\hline $199-\mathrm{N}-75$ & B0СТ46 & 1,760 & $2,822,000$ & 37,000 & 8.439 & 0.111 & $5.05 \mathrm{E}-12$ & 0.167 \\
\hline 299-E17-9 & B0СТ47 & 5,062 & $2,140,000$ & 140,000 & 18.42 & 2.06 & $1.10 \mathrm{E}-11$ & 0.364 \\
\hline 299-E17-9 & B0CT48 & 5,062 & $2,060,000$ & 270,000 & 17.72 & 2.29 & $1.06 \mathrm{E}-11$ & 0.350 \\
\hline 299-E33-10 & В0СТ51 & 16,639 & 147,000 & 2,100 & 4.16 & 0.06 & $2.49 \mathrm{E}-12$ & 0.0821 \\
\hline 299-W14-12 & В0СТ52 & 86,269 & $5,410,000$ & 120,000 & 793 & 18 & $4.74 \mathrm{E}-10$ & 15.7 \\
\hline 299-W22-9 & В0СТ53 & 13,184 & $1,204,000$ & 88,000 & 27.0 & 1.96 & $1.61 \mathrm{E}-11$ & 0.532 \\
\hline 399-1-16A & B0CT55 & 13,440 & 80,700 & 1,400 & 1.843 & 0.032 & $1.10 \mathrm{E}-12$ & 0.0364 \\
\hline 699-17-70 & B0CT56 & 10,931 & 713 & 279 & 0.013 & 0.005 & $7.77 \mathrm{E}-15$ & 0.00026 \\
\hline 699-19-43 & B0CT58 & 6,896 & 604 & 98 & 0.00708 & 0.00115 & 4.23E-15 & 0.000140 \\
\hline 699-24-33 & В0СТ59 & 6,863 & 132,600 & 4,500 & 1.545 & 0.052 & $9.24 \mathrm{E}-13$ & 0.0305 \\
\hline 699-40-1 & B0CT60 & 9,083 & 512,000 & 5,900 & 7.9 & 0.092 & 4.72E-12 & 0.156 \\
\hline 699-55-89 & B0CT61 & 6,534 & $<15,000$ & & $<0.167$ & & & \\
\hline 699-62-31 & B0CT62 & 8,376 & 18,890 & 660 & 0.2688 & 0.0093 & $1.61 \mathrm{E}-13$ & 0.00531 \\
\hline 699-65-72 & B0CT63 & 6,943 & 258,900 & 3,200 & 3.054 & 0.038 & $1.83 \mathrm{E}-12$ & 0.0603 \\
\hline 699-S19-E13 & В0СТ64 & 12,792 & 123,000 & 36,000 & 2.67 & 0.77 & $1.60 \mathrm{E}-12$ & 0.0527 \\
\hline
\end{tabular}

Chlorine-36 is a long-lived radionuclide (half life of 301,000 years) with a high mobility in the vadose zone and groundwater. It is produced in reactor operations as an activation product of chlorine-35. Chlorine-36 in the environment also results from a small amount of natural atmospheric and subsurface production and from atmospheric nuclear testing in the 1950s and 1960s. This isotope can provide valuable information on the movement of water and contamination in the vadose zone and groundwater.

Chlorine-36 has been used as a tracer for vadose zone recharge studies at Hanford (Prych 1995; Murphy et al. 1996). Although chlorine-36 in the vadose zone and groundwater may be present due to atmospheric fallout and a small subsurface production rate, chlorine-36 in groundwater at several DOE sites has been shown to result from reactor operations (Beasley et al. 1992; Beasley et al. 1993).

Little information currently exists on chlorine-36 in the sources or the distribution in groundwater or vadose zone at the Hanford Site. Chlorine-36 is expected mainly to stay in the aqueous streams and, thus, much chlorine-36 may have remained with the high activity fission products in the tank waste streams and a component will be present in other aqueous streams. Some volatilization may have occurred and should be evaluated. 
Pre-bomb pulse chlorine-36:chloride ratios at Hanford are estimated to be $735-876 \times 10^{-15}$ with bomb pulse levels increasing to approximately 4,000 - 8,000 $10^{-15}$. Deep groundwater in the Columbia River Basalts has reported ratios of $7-1,130 \times 10^{-15}$ (Gifford et al. 1985). Thus, the shallow groundwater samples range from low levels consistent with pre-bomb pulse background to levels over 4 orders of magnitude greater than the bomb-pulse ratios $\left(604-216,000,000 \times 10^{-15}\right)$. The levels clearly show a large Hanford Site contribution. By contrast, the ratios reported at the Savannah River Site ranged from $61-4,452 \times 10^{-15}$ (Beasley et al. 1992). Ratios reported at Idaho National Environmental Engineering Laboratory ranged from $539-1,560,000 \times 10^{-15}$ (Beasley et al. 1993). The Hanford production and release of chlorine-36 appears to have been significantly greater than at the other sites.

The high concentrations of chlorine- 36 seen in the $100 \mathrm{~F}$ and $\mathrm{K}$ Areas were unexpected. Some chlorine-36 may have been formed by activation of chlorine in the cooling water but chlorine concentration in the Columbia River, used for cooling water, are low and the residence time in the reactors is not great for the single-pass cooling used in early reactors.

The fate of chlorine-36 in the fuel processing is unknown. Chlorine chemistry is similar to iodine so it is likely that a fraction of the chlorine-36 was released to the atmosphere with the iodine-129 and -131 . Beasley et al. 1993 postulate that chlorine-36 is released as chlorine gas and as NOCl. Because of the long half-life of chlorine-36, it is likely that breakthrough occurred on the silver scrubbers that were designed to remove iodine-131 from the stack release. If this is the case, then chlorine-36 would have been released to the atmosphere through the entire period of Hanford operations. The limited groundwater data show that chlorine-36 also is found in the large-volume liquid releases to cribs during processing. The chlorine-36 correlates poorly with tritium, indicating that these two mobile species provide complementary information on groundwater contamination (Figure 4.13).

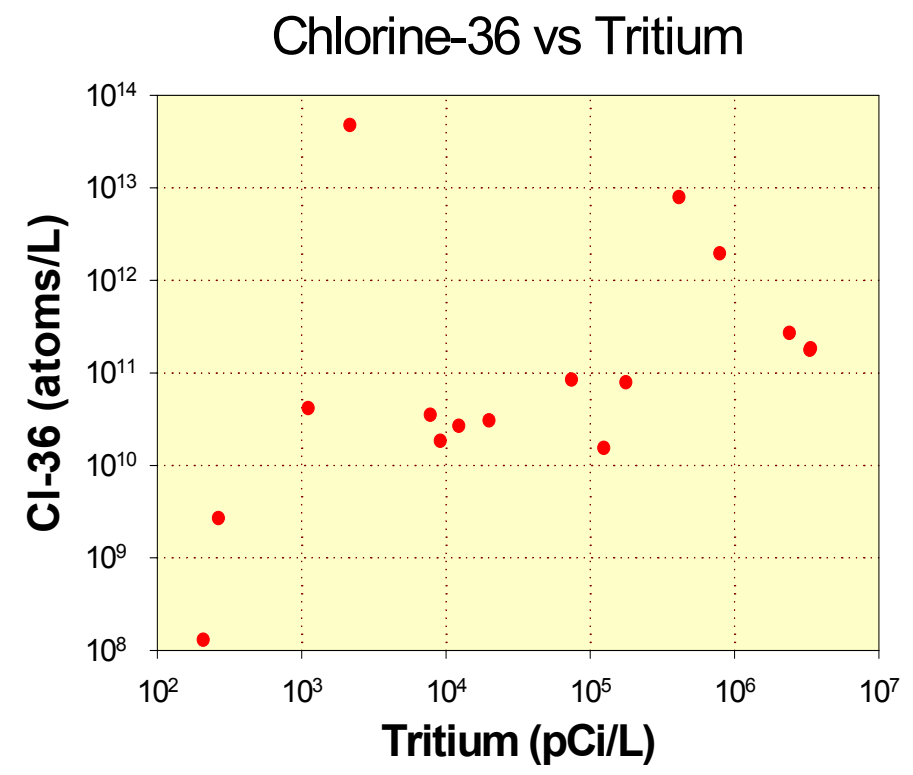

Figure 4.13. Chlorine-36 Concentration Compared to Tritium for Hanford Groundwater Samples 


\subsection{Conclusions}

The application of new ICP-MS measurement techniques to groundwater samples has expanded our ability to distinguish commingled contaminant plumes and to relate plumes to sources. The limited sampling performed to date has shown the applicability of the methods and some preliminary conclusions can be drawn. Uranium and ruthenium isotopes in groundwater show different compositions that can be related to different plumes and/or sources. The plutonium isotopes are consistent with known contaminant sources, but the limited mobility and limited extent of known plumes means that broader application as a contaminant signature will require an evaluation of the plutonium isotopes at considerably lower concentration levels. Lower level measurements are attainable by processing greater sample volume and by using improved instruments now available. To date, fission-derived molybdenum has not been identified in groundwater but the presence of fission molybdenum in the SX tank farm vadose zone suggests that further analyses of groundwater may be useful.

The measurement of uranium isotopes can show the difference between different site and offsite sources of uranium. The presence of uranium-236 is diagnostic of uranium of anthropogenic origin. The uranium detected in one well in the southern part of the site, shows an isotopic composition consistent with manufacture of commercial fuel elements. The uranium near the 618-10 burial ground is depleted in uranium-234 and -235 and likely came from 300 Area research waste. Uranium in the northern 200 East Area, near B Plant, is dominated by material processed from early Hanford reactor operations, consistent with an origin at B Plant. The uranium isotopic data agree well with what is known from computer modeling the isotopic composition of Hanford reactor fuel.

Ruthenium of fission origin is seen in groundwater from the vicinity of B Plant in the 200 East Area. Its extent has not been fully evaluated but the data indicate that the ruthenium is lower in concentration relative to technetium-99 than would be predicted strictly from their uranium and/or plutonium fission yields. The samples from the southeastern wells sampled have higher technetium-99:ruthenium-101 ratios than the wells further northwest. This suggests distinct sources for the contamination.

Further research to confirm these results and to extend knowledge of isotopic distributions would be useful. Sampling of groundwater for uranium isotopic composition should continue, focusing on areas of significant uranium contamination, such as the 300 Area and the U Plant region of 200 West Area. A baseline of offsite uranium isotopic composition should be developed to deal with questions of offsite migration. The molybdenum analysis should continue to determine if fission molybdenum is generally absent from the groundwater or if the absence is related to the specific areas sampled. The relationship between ruthenium isotopes and technetium appears productive for distinguishing technetium sources. Further plutonium work should be considered if there are locations where it may help constrain contaminant sources. The plutonium work would need to concentrate reducing detection limits.

Interpretation of the groundwater composition would benefit from further research of isotopic composition of source area vadose zone samples. Although some work has been done on the SX tank farm, this has not been extended to other tank farms. No work has been done yet on the liquid waste sites. 
Method development for the ICP-MS should continue. The molybdenum, ruthenium, rhodium, and palladium method needs some minor refinements. New ICP-MS capabilities for high precision and high sensitivity measurement are being added at PNNL and they should be evaluated so the better quality results can be obtained. Several other isotopes show promise for interpreting site contamination. These include cesium-135 and -137 , selenium-79, -80 , and -82 , iodine-127 and -129 . The ICP-MS methods for neptunium-237 and americium-241 may be useful in some areas.

The chlorine-36 work from previous years indicates that further investigation may be productive in distinguishing between contaminant sources. The wide range in concentrations and the high sensitivity of the accelerator mass spectrometry technique suggest a broad applicability on site. However, the analyses are fairly expensive and time consuming. The high concentrations also mean that particular care must be taken not to overwhelm the mass spectrometer and to avoid contaminating the laboratory. 


\subsection{References}

Beasley, T.M., D. Elmore, P.W. Kubik, and P. Sharma. 1992. "Chlorine-36 Releases from the Savannah River Site Nuclear Fuel Reprocessing Facilities.” Groundwater 30:539-548.

Beasley, T.M., L.D. Cecil, P. Sharma, P.W. Kubik, U. Fehn, L.J. Mann, and H.E. Gove. 1993. "Chlorine-36 in the Snake River Plain Aquifer at the Idaho National Engineering Laboratory: Origin and Implications." Groundwater 31:302-310.

Buessler, K.O. 1997. “The Isotopic Signature of Fallout Plutonium in the North Pacific.” J. Environ. Radioactivity, 36:69-83.

DOE. 1996. Plutonium: The First 50 Years. DOE/DP-0137, U.S. Department of Energy, Washington, D.C.

Dresel, P.E. 1997. "Occurrence of Chlorine-36 in Groundwater at the Hanford Site, Washington." Abstract for the Second Symposium on the Hydrogeology of Washington State. Washington State Department of Ecology, Olympia, Washington.

Fleischer, R.L. 1980. "Isotopic Disequilibrium of Uranium: Alpha-Recoil Damage and Preferential Solution Effects." Science 207(29):979.

Gifford, S., H. Bentley, and D.L. Graham. 1985. "Chlorine Isotopes as Environmental Tracers in Columbia River Basalt Groundwaters.” In Proceedings, Part 1, Hydrogeology of Rocks of Low Permeability, International Association of Hydrogeologists Memoires, vol. 17, Tucson, Arizona.

Gumprecht, R.O. 1954. Plutonium Product Quality. HW-31952, General Electric Hanford Atomic Products Operation, Richland, Washington.

Jones, T.E., B.C. Simpson, M.I. Wood, and R.A. Corbin. 2001. Preliminary Inventory Estimates for Single-Shell Tank Leaks in B, BX, and BY Tank Farms. RPP-7389, CH2M HILL Hanford Group, Inc., Richland, Washington.

Kelley, J.M., L.A. Bond, and T.M. Beasley. 1999. “Global Distribution of Pu Isotopes and ${ }^{237} \mathrm{~Np} . S c i$. Tot. Environ. 237/238:483-500.

Murphy, E.M., T.R. Ginn, and J.L. Phillips. 1996 "Geochemical Estimates of Paleorecharge in the Pasco Basin: Evaluation of the Chloride Mass Balance Technique.” Wat. Resour. Res. 32(9):2853-2868.

Osmond, J.K., and J.B. Cowart. 1976. "The Theory and Uses of Natural Uranium Isotopic Variations in Hydrology." Atomic Energy Review 14(4):621-679. 
Prych, E.A. 1995. Using Chloride and Chlorine-36 as Soil-Water Tracers to Estimate Deep Percolation at Selected Locations on the U.S. Department of Energy Hanford Site, Washington. Open-file Report 94-514, U.S. Geologic Survey, U.S. Department of the Interior, Washington, D.C.

Smith, R.M. 1980. 216-B-5 Reverse Well Characterization Study. RHO-ST-37, Rockwell International, Richland, Washington.

Watrous, R.A. and D.W. Wootan. 1997. Activity of Fuel Batches Processed through Hanford Separations Plants, 1944 through 1989. HNF-SD-WM-TI-794, Rev. 0, Lockheed Martin Hanford Corporation, Richland, Washington. 


\section{Distribution}

No. of

\section{Copies}

OFFSITE

M. Conrad

Building 70A, Room 4418

Lawrence Berkeley National Laboratory

1 Cyclotron Road

Berkeley, CA 94720

D. DePaolo

Earth and Planetary Science

Department MC4767

McCone Hall

University of California

Berkeley, CA 94720-4767

\section{ONSITE}

\section{DOE Richland Operations Office}

M. J. Furman

J. P. Hanson

R. D. Hildebrand

K. M. Thompson

DOE Office of River Protection
No. of

Copies

2 Bechtel Hanford, Inc.

J. V. Borghese

$\mathrm{H} 0-19$

S. W. Petersen

$\mathrm{H} 0-23$

\section{Pacific Northwest National Laboratory}

P. E. Dresel (5) K6-96

G. C. Eiden P7-07

J. C. Evans K6-96

O. T. Farmer III P8-08

M. D. Freshley H0-21

J. S. Fruchter K6-96

G. W. Gee K9-33

D. G. Horton K6-81

D. W. Koppenaal K8-98

S. P. Luttrell K6-96

S. M. Narbutovskih K6-96

K. B. Olsen K6-96

R. J. Serne K6-81

R. M. Smith K6-96

E. C. Thornton K6-96

J. M. Zachara L8-96

Hanford Technical Library (2) P8-55

R. M. Yasek H6-60

3 CH2M HILL Hanford Group, Inc.

T. E. Jones

L7-12

F. M. Mann

$\mathrm{H} 0-22$

D. A. Myers

$\mathrm{H} 0-22$ 